\title{
Between-year changes in community composition shape species' roles in an Arctic plant-pollinator network
}

Alyssa Cirtwill, Tomas Roslin, Claus Rasmussen, J ens Mogens Olesen and Daniel B. Stouffer

The self-archived postprint version of this journal article is available at Linköping University Institutional Repository (DiVA):

http:/ / urn.kb.se/ resolve?urn=urn:nbn:se:liu:diva-150219

N.B.: When citing this work, cite the original publication.

Cirtwill, A., Roslin, T., Rasmussen, C., Olesen, J. M., Stouffer, D. B., (2018), Between-year changes in community composition shape species' roles in an Arctic plant-pollinator network, Oikos, 127(8), 11631176. https:// doi.org/ 10.1111/ oik.05074

Original publication available at:

https:// doi.org/ 10.1111/ oik.05074

Copyright: WILEY

Publisher URL Missing 


\title{
Between-year changes in community composition shape species' roles in an Arctic plant-pollinator network
}

\author{
Alyssa R. Cirtwill ${ }^{1,2 \dagger}$, Tomas Roslin ${ }^{3,4}$, Claus Rasmussen ${ }^{5}$, Jens Mogens \\ Olesen $^{6}$, Daniel B. Stouffer ${ }^{1}$ \\ ${ }^{1}$ Centre for Integrative Ecology \\ School of Biological Sciences, University of Canterbury \\ Private Bag 4800, Christchurch 8140, New Zealand \\ 2 Present address: Department of Physics, Chemistry, and Biology (IFM) \\ Linköping University \\ 58183 Linköping, Sweden \\ ${ }^{3}$ Department of Ecology \\ P.O. Box 7044, Swedish University of Agricultural Sciences \\ SE-750 07 Uppsala, Sweden \\ ${ }^{4}$ Spatial Foodweb Ecology Group \\ Department of Agricultural Sciences \\ PO Box 27 (Latokartanonkaari 5) \\ FI-00014 University of Helsinki, Finland \\ ${ }^{5}$ Department of Bioscience, Aarhus University \\ Ole Worms Allé 1, DK-8000 Aarhus C, Denmark \\ ${ }^{6}$ Department of Bioscience, Aarhus University \\ Ny Munkegade 114, DK-8000 Aarhus C, Denmark \\ $\dagger$ Corresponding author: \\ alyssa.cirtwill@gmail.com
}

ORCiD: 0000-0002-1772-3868 


\section{Abstract}

Inter-annual turnover in community composition can affect the richness and functioning of ecological communities. If incoming and outgoing species do not interact with the same partners, ecological functions such as pollination may be disrupted. Here, we explore the extent to which turnover affects species' roles - as defined based on their participation in different motifs positions- in a series of temporally replicated plant-pollinator networks from high-Arctic Zackenberg, Greenland. We observed substantial turnover in the plant and pollinator assemblages, combined with significant variation in species' roles between networks. Variation in the roles of plants and pollinators tended to increase with the amount of community turnover, although a negative interaction between turnover in the plant and pollinator assemblages complicated this trend for the roles of pollinators. This suggests that increasing turnover in the future will result in changes to the roles of plants and likely those of pollinators. These changing roles may in turn affect the functioning or stability of this pollination network.

\section{Keywords}

pollination; network structure; inter-annual variation; intra-annual variation; turnover 


\section{Introduction}

One of the few constants in studies of ecological communities is that their composition inevitably changes over time. Indeed, temporal turnover of species is a keystone of MacArthur \& Wilson's theory of island biogeography (MacArthur and Wilson 1967, Hubbell 2009) and has been empirically observed in communities ranging from mangrove arthropods (Simberloff and Wilson 1969) to seabirds (Diamond 1969). Turnover may change the richness of a community if immigration and extinction rates are not equal (Simberloff and Wilson 1969, Flenner and Sahlén 2008), leading to changes in community stability and ecosystem functioning (Knops et al. 1999, Ives and Carpenter 2007). Moreover, changes in community composition can directly affect ecosystem functioning and services (Burkle et al. 2013), even if species richness does not change.

This possibility seems particularly likely when ecosystem functions are viewed through the lens of interaction networks. In such webs, most species typically interact with only a subset of the community (Waser et al. 1996). Such restrictions on interactions may arise from simple limits on foraging time, or because species can only interact with partners with specific traits (Vizentin-Bugoni et al. 2014, CaraDonna et al. 2017, Weinstein and Graham 2017). In the context of plant-pollinator networks, there is an extensive literature documenting trait matching between plants and flower visitors (e.g., Motten 1986, Fenster et al. 2004, Ollerton et al. 2009). These traits may be morphological (e.g., corolla depth, flower colour, and proboscis length) or behavioural (e.g., pollinator foraging strategy and the daily timing of flower opening; Vázquez et al. 2009). Moreover, both types of traits may either facilitate interactions when plants and pollinators have complementary traits (e.g., flower colour and scent that match pollinator preferences) or act as barriers to interaction between species with incompatible traits such as diurnal pollinators and night-flowering plants (Vázquez et al. 2009).

If incoming and outgoing species do not have similar traits, changes to the composition of a community are likely to affect the availability of suitable interaction partners for each species. If, on the other hand, incoming species are compatible with species already present in a network, some interactions could be "rewired" (i.e., some species may swap interaction partners [Bascompte and Melián 2005]) such that newly-arrived species are added to the interaction partners of pre-existing species (Olesen et al. 2011, Emer et al. 2016). As species also affect each other indirectly through competition and facilitation (Mitchell et al. 2009, Stouffer et al. 2014), any changes to the availability of interaction partners are likely to have knock-on effects on other interactions, affecting species' roles in their communities as a whole. Such cascading effects have been dramatically demonstrated after the introduction of invasive herbivores and subsequent changes to local plant communities (Nuñez et al. 2010). They have also been observed after the restoration of wolves to Yellowstone National Park which led to increased bird diversity through indirect effects of wolves on the plant assemblage (Dobson 2014).

Arctic plant-pollinator networks in particular are likely to experience very high amounts of turnover because of the large inter-annual variation in temperature and precipitation in Arctic environments (Hanssen-Bauer and Førland 1998, Kankaanpää et al. 2018). Changes in the onset of snowmelt or air temperature can dramatically affect the phenologies of Arctic plants and arthropods (Høye et al. 2007, Høye and Forchhammer 2008, Høye et al. 
2013, Schmidt et al. 2016, Kankaanpää et al. 2018). These variable phenologies may affect which species co-occur in time and hence are available to interact in a plant-pollinator network in a given year (Simanonok and Burkle 2014), with knock-on effects on indirect interactions. As many of the species in this system are active for very short time periods (Olesen et al. 2008), even a small change in phenology may be enough to prevent an interaction (Høye et al. 2013). This phenomenon has also been observed in alpine plant-pollinator systems where turnover is high over the course of a growing season. This turnover is, as in the Arctic, associated with changes in the interactions that occur and in overall network structure (Simanonok and Burkle 2014, Cuartas-Hernández and Medel 2015, CaraDonna et al. 2017). Note that species may also switch interaction partners in response to changing abundances, even if their earlier interaction partners are still present and active (Carnicer et al. 2009). Just like changes in phenology, this switching would result in changes to species' direct and indirect interactions (i.e., their roles in the network) over time, but these changes would not be associated with turnover.

Tracking changes to direct and indirect interactions requires a meso-scale approach to network structure. Macro-scale or network-level measures of network structure such as nestedness can mask substantial differences between networks (Stouffer et al. 2012, Baker et al. 2015, Baker 2015). Micro-scale measures such as lists of interaction partners, on the other hand, do not convey any information about the indirect interactions which knit together a community. Using meso-scale motifs (unique patterns of $n$ interacting species) to quantify species' roles in a network avoids these issues by providing a species-level view of networks that includes both direct and indirect interactions (Cirtwill and Stouffer 2015). Motifs can be thought of as the building blocks of networks (Milo et al. 2002, 2004, Stouffer et al. 2007, Baker et al. 2015), and each motif represents a different way in which sets of species interact, and hence a unique contribution to ecosystem processes (e.g., pollination or energy flows) within a community. Although the use of motifs in bipartite networks is still in its infancy, results from unipartite food webs suggest that different motifs also make different contributions to network stability (Kondoh 2008, Stouffer and Bascompte 2010, Borrelli et al. 2015). It is reasonable to expect that further research may reveal similar relationships between stability and the frequency of various motifs in bipartite networks.

Here we use motifs to explore the effects of turnover on species' direct and indirect interactions using a temporally-replicated set of four plant-pollinator networks from Zackenberg, Greenland. Within this framework, we test three specific expectations. As the first and last of these networks are separated by 15 years and because there has been substantial warming and change in the timing of snowmelt over this period (Høye et al. 2013, Kankaanpää et al. 2018) we expect (1) that there has been substantial change in the composition of the plant and/or pollinator assemblages at this site. As changes to the plant-pollinator community would likely also alter the pollination interactions occurring, we also expect that (2) species' roles within the pollination network will have changed over time, and (3) with greater changes in community composition leading to greater changes in roles. To examine these expectations, we use a species-level framework that gives us a more detailed perspective than would other, network-level metrics. 


\section{Materials and Methods}

\section{Study site and data collection}

We use plant-pollinator data sampled at the Zackenberg research station in High Arctic NE Greenland ( $74^{\circ} 28^{\prime} \mathrm{N}, 20^{\circ} 35^{\prime} \mathrm{W}$ ) over four summers: in 1996 and 1997 (Olesen et al. 2008) and 2010 and 2011 (Rasmussen et al. 2013). Each study period lasted from the last snowmelt in spring to the first frost and snowfall in autumn. In 1996 and 1997, this covered 43 and 69 days, respectively, of which 25 in each year had sufficiently fine weather to permit observation (Olesen et al. 2008). In 2010 and 2011, the study period covered 70 and 69 days, respectively, of which 54 and 52 days were spent observing in the field (Rasmussen et al. 2013). All observation days had weather suitable for foraging insects (i.e., no rain, snow, or strong winds). During each field day (lasting from 09:00 to 17:00), two individuals of each species of flowering plant were observed for 20 minutes each (i.e., 40 minutes of observation for each plant species per day), and all insect visitors to flowers were recorded as potential pollinators (Olesen et al. 2008, Rasmussen et al. 2013). For further details about interaction sampling methods, see Olesen et al. (2008) and Rasmussen et al. (2013). To see whether the different number of sampling days in each year was likely to affect our results, we plotted accumulation curves for plants, pollinators, and interactions (Supplementary material Appendix A1, Fig. A1). The level of saturation in each curve was similar across years.

\section{Quantifying species turnover}

We began by quantifying the amount of turnover in plants and pollinators between years. For each pair of years, we calculated Whittaker's beta diversity index $\left(\beta_{W}\right.$; Whittaker 1972). This index, $\beta_{W}=(\gamma-\alpha) / \alpha$, compares the total number of species detected across both years $(\gamma)$ with the mean number of species detected in each of the two years $(\alpha)$ and varies between 0 (identical species in both years) and 1 (complete turnover of the assemblage). We calculated turnover separately for the plant and pollinator assemblages. In addition, we counted the number of plants and pollinators that were observed in both years (persistent species), that were observed in the earlier year but not the later year (disappearing species), and that were observed in the later year but not the earlier year (newly-arrived species). Importantly, we do not argue that these species have appeared or disappeared from the full study region during the focal time period, only that their abundances have increased above or decreased under a detection threshold (cf. the concept of functional extinction). This is in line with the view of interaction turnover given in Simanonok and Burkle (2014) but contrasts with other concepts of species turnover which require the complete removal of species from a site (Simanonok and Burkle 2014).

To obtain a more detailed perspective, we also considered turnover within years. For each pair of months within a year, we calculated $\beta_{W}$ and counted numbers of persistent, disappearing, and newly-arrived species as described above. To account for variation within years when exploring variation between years, we also calculated turnover and numbers of persistent, disappearing, and newly-arrived species across years within the same month (e.g., June 1996 and June 2010). 
Of the observations collected in 1996, 94 were not precisely dated and were instead associated with a range of tentative dates. To account for these observations, we calculated turnover using three different methodologies. Specifically, we included the tentatively-dated observations only in networks covering the best-guess date of observation, included them only in the yearly networks (i.e., excluded from the monthly networks), or included them in for each network covering any part of the range of tentative dates (see Supplementary material Appendix A2 for details). As the method of including the tentatively-dated observations did not substantially change our results (Supplementary material Appendix A3), we therefore present results based on networks which included the tentatively dated observations only in the networks describing the best guess for the date of observation. This approach preserves the number of interactions that were actually observed.

\section{Quantifying species roles}

Next, we compiled plant-pollinator networks for each year (1996, 1997, 2010, and 2011) and for each month of sampling within each year (June, July, August), obtaining 16 networks in total (four yearly networks and 12 monthly networks). After assembling the interaction networks, we described species' roles within each network in terms of their participation in two- to six-species "motifs" (Fig. 1; Supplementary material Appendix A4, Fig. A2). Within each motif, there are two or more unique positions describing exactly how each plant and pollinator contributes to the motif (Baker et al. 2015). The vector listing the number of times a species appears in each position in each motif (74 positions in total) therefore provides a detailed, multivariate description of the ways in which a species participates in these plant-pollinator networks and how pollination may be changing over time. As with turnover, we assembled monthly networks and calculated roles using different methods of accounting for tentatively-dated observations; the method of accounting for these observations again did not affect our conclusions and so we report only the results when tentatively-dated observations were included in webs containing the best-guess date only. For other methods of dealing with the tentatively-dated observation see Appendices A2-A3.

\section{Comparing roles over time}

Having determined each species' role in each network, we wished to compare the roles of each species between and within years to test whether roles changed over time and, more importantly, whether changes in roles were related to changes in community composition. To do this, we first quantified differences between species' roles (i.e., vectors of frequencies of different motif positions) using Bray-Curtis dissimilarity (Anderson 2001, Baker et al. 2015). This dissimilarity measures differences between roles based only on positions which appear in at least one role. Thus, two species will not appear to have more similar roles just because they have a large number of shared "double zeros" (positions which do not appear in either network). We then used a non-parametric permutational multi-variate analysis of variance (PERMANOVA; Anderson 2001) to test whether dissimilarity in species' roles in different webs was related to the year in which the webs were assembled. For the monthly webs, we followed this year-by-year analysis with a second PERMANOVA 
testing whether dissimilarity in species' roles was related to the month, year, and month-year combination in which the webs were sampled.

Similar to a traditional ANOVA, a PERMANOVA uses a pseudo- $F$ statistic to compare differences among and within groups. As part of this calculation, spatial medians (or multivariate centroids) are calculated for each group. These medians are the roles with minimal distance to all other roles in the group (Anderson 2001), and are analogous to univariate means in an ANOVA. Unlike an ANOVA, however, the PERMANOVA does not assume that the data follow any particular distribution. Instead, the raw data are permuted to obtain the null distribution of the test statistic and a $p$-value is computed using this distribution. We stratified permutations by species such that the roles belonging to one species could be shuffled between years but the roles of one species could not be shuffled with those of another. This prevents variation in the roles of different species from masking variation within the roles of a single species. This stratification also means that, although the roles of species occurring in only one network were not excluded from our analyses, such species did not contribute to significance testing. They were, however, included in our calculation of the median role in each network. We conducted separate tests for the roles of plants and pollinators in the monthly and yearly webs (six PERMANOVAs in total) and used 9999 permutations to calculate the null distribution in all cases. All PERMANOVAs were performed using the adonis function in the R (R Core Team 2014) package vegan (Oksanen et al. 2012).

As differences in the dispersion of roles about their group median can lead to false positives in PERMANOVA tests, we tested whether dispersions of plants' and pollinators' roles were different between years. We quantified dispersions using the betadisper function in the $\mathrm{R}$ ( $\mathrm{R}$ Core Team 2014) package vegan (Oksanen et al. 2012). After quantifying dispersions, we tested whether they varied between years using a one-way ANOVA.

Different dispersions across years would mean that significant PERMANOVA results must be treated with caution.

To visualise the change in species' roles over time, we performed a non-metric multidimensional scaling (NMDS) analysis to align the roles of plants or pollinators in all networks along two major axes explaining the most variation in structure (analysing plant and pollinator assemblages separately since the two groups never occur in the same motif positions). Importantly, the NMDS plots offer only indirect illustrations of the PERMANOVA results as they compress the higher-dimensional comparison of the PERMANOVA into two dimensions for visualisation purposes. We analysed the roles of species in yearly and monthly networks together using the metaMDS function in the R ( $R$ Core Team 2014) package vegan (Oksanen et al. 2012).

\section{Linking turnover and change in roles}

Finally, to test whether the amount of turnover in the plant, pollinator, or both assemblages was related to the amount of dissimilarity in species' roles, we performed a logistic regression of the Bray-Curtis dissimilarity (which is bounded between 0 and 1) between pairs of roles for the same species in different webs against the $\beta_{W}$ for plants, $\beta_{W}$ for pollinators, and their interaction between the two webs. As there were only four yearly webs, providing insufficient power to fit our model, we used species' roles and dissimilarities 
for the monthly webs in the regression and did not perform these analyses for the yearly webs. To account for the possibility that the roles of some species (e.g., species which were rarely observed; see e.g., Fort et al. 2016) may have more variable roles between years regardless of the effects of turnover, we included a random effect of species ID. Differences in the variability of roles over time across species is an interesting question in its own right, but investigating this is beyond the scope of the present work. With all of the above fixed and random effects we obtain a regression of the form:

$$
\operatorname{logit}\left(\Delta_{x i j}\right) \approx \beta_{W_{i j}}^{\text {plants }}+\beta_{W_{i j}}^{\text {pollinators }}+\left[\beta_{W_{i j}}^{\text {plants }} \times \beta_{W_{i j}}^{\text {pollinators }}\right]+S_{x}
$$

where $\operatorname{logit}\left(\Delta_{x i j}\right)$ is the logit-transformed dissimilarity in the roles of species $x$ in webs $i$

and $j, \beta_{W_{i j}}^{\text {plants }}$ is the turnover in the plant assemblage between webs $i$ and $j, \beta_{W_{i j}}^{\text {pollinators }}$ is the turnover in the pollinator assemblage between webs $i$ and $j$, and $S_{x}$ is the random effect for species $x$. If after fitting the regression, the interaction term was not significant, we then re-fit the regression including only the main effects of $\beta_{W_{i j}}^{\text {plants }}$ and $\beta_{W_{i j}}^{\text {pollinators }}$. We also conducted separate regressions for the roles of plants and those of pollinators, to allow us to distinguish between trends in the different groups. As it is impossible to calculate dissimilarities for species that appear in only a single year/month combination, any such species (four plants and 35 pollinators in total) were excluded from our analyses.

Because each species' role in each network will be included as part of several dissimilarities, we considered the degrees of freedom for this regression to be the number of species (plants and pollinators) included in the regressions rather than the number of role-pair combinations. To allow us to distinguish between within-year and between-year comparisons, we repeated this regression analysis first using only within-year dissimilarities and turnovers and second using only between-year dissimilarities and turnovers. Following our procedure for measuring turnover between years, we included only between-year dissimilarities that were between webs describing the same month. All regressions were performed using the glmer function in the $\mathrm{R}$ ( $\mathrm{R}$ Core Team 2014) package lmerTest (Kuznetsova et al. 2014) with a logit link function.

\section{Results}

\section{Did community composition change over time?}

Both the richness and composition of the Zackenberg plant-pollinator community varied between years. While numbers of plant species were relatively constant over time, more pollinator species were observed in each year from 1996 to 2011 (Supplementary material Appendix A4, Fig. A3a-b). Similarly, few plants but many pollinators either appeared or disappeared between years (Supplementary material Appendix A4, Fig. A3c-d). There was little turnover among plants for any pair of years $\left(0.00 \leq \beta_{W} \leq 0.169 ;\right.$ Supplementary material Appendix A5, Table A5). Among pollinators, turnover was higher in all pairs of years $\left(0.203 \leq \beta_{W} \leq 0.432\right)$.

Within each year, turnover was high for both plants and pollinators (Supplementary material Appendix A5, Table A6). In both cases, turnover was lower between consecutive months (June-July or July-August; $0.287 \leq \beta_{W_{\text {pollinators }}} \leq 0.513$ and $0.224 \leq \beta_{W_{\text {plants }}} \leq$ 
0.476) than between June and August $\left(0.672 \leq \beta_{W_{\text {pollinators }}} \leq 0.784\right.$ and $0.514 \leq \beta_{W_{\text {plants }}} \leq$ 0.750). Between years, turnover was generally lower in July $\left(0.333 \leq \beta_{W_{\text {pollinators }}} 0.453\right.$ and $\left.0.091 \leq \beta_{W_{\text {plants }}} \leq 0.241\right)$ than in June or August $\left(0.500 \leq \beta_{W_{\text {pollinators }}} \leq 0.596\right.$ and $0.400 \leq$ $\beta_{W_{\text {pollinators }}} \leq 0.877 ; 0.280 \leq \beta_{W_{\text {plants }}} \leq 0.385$ and $0.231 \leq \beta_{W_{\text {plants }}} \leq 0.46$, respectively).

\section{Did species' roles change over time?}

The roles of plants in the yearly networks changed significantly between years $\left(F_{1,126}=5.76\right.$, $p<0.001$; Table 1; Fig. 3a). The roles of plants in the monthly networks also changed significantly between years, although the difference between mean within-group and between-group dissimilarities was smaller than in the yearly networks $\left(F_{1,230}=3.31\right.$, $p=0.001$; Table 1 ). When we added terms for month and month-year combination to the PERMANOVA, plants' roles in the monthly networks varied significantly between months and month-year combinations as well as years $\left(F_{2,226}=6.62, p<0.001 ; F_{2,226}=2.89, p=0.023\right.$; and $F_{1,226}=3.52, p=0.001$, respectively; Fig. 3c,e,g). Differences between mean within-group and between-group dissimilarities were much larger when comparing across months or month-year combinations than when comparing across years (Table 1).

Like plants' roles, pollinators' roles in the yearly networks varied significantly between years $\left(F_{1,287}=13.6, p<0.001\right.$; Table 1 Fig. $\left.3 \mathrm{~b}\right)$. In the monthly networks, pollinators' roles also varied significantly between years $\left(F_{1,456}=9.35, p<0.001\right)$. The difference between mean within-group and between-group dissimilarities was again smaller in the monthly networks than in the yearly networks (Table 1). When terms for month and year-month combination were added to the PERMANOVA, pollinators' roles varied significantly between months and month-year combinations $\left(F_{2,451}=4.16, p<0.001\right.$; and $F_{1,451}=9.90$, $p<0.001$, respectively; Fig. 3d,f,h). Differences between mean within-group and between-group dissimilarities were again much larger when comparing across months or month-year combinations than when comparing across years (Table 1).

As different dispersions in different groups can lead to false positives in PERMANOVA tests, we also compared dispersions corresponding to the groups in each of our PERMANOVA tests. For both plants and pollinators, the dispersion of roles in the yearly networks did not vary between years $\left(F_{3,124}=1.49, p=0.221\right.$ for plants and $F_{3,285}=0.763$, $p=0.515$ for pollinators). This means that the significant change in roles between years is not a statistical artefact.

The dispersion of plants' and pollinators' roles in the monthly networks, however, did vary significantly between years $\left(F_{3,228}=4.16, p=0.007\right.$ for plants and $F_{3,453}=3.72, p=0.011$ for pollinators). Dispersion of plants' roles also varied significantly between year-month combinations $\left(F_{11,220}=3.55, p<0.001\right)$ while dispersion of pollinator roles did not vary significantly between month-year combinations $\left(F_{11,445}=0.962, p=0.481\right)$. This means that it is possible that different dispersions between years lead to some of our significant PERMANOVA results for the monthly webs. Nevertheless, based on the differences in median roles displayed in the NMDS (e.g., between June 1996 and 2010 or any pair of August webs or between June 1997 and 2010 or August 1996 and 2011 for pollinators; Fig. 3c-h) we consider this explanation to be unlikely. That is, the fact that the median roles of some monthly webs were visually different between years suggests that the significant PERMANOVA result is not an artefact of the different dispersions in different 
years. We therefore do not believe that these changing dispersions have greatly affected our results.

\section{Was amount of turnover related to change in roles?}

\section{All comparisons}

For plants' roles, the amount of change (dissimilarity) was not related to the interaction term for turnover in the plant and pollinator assemblages $\left(\left[\beta_{W_{i j}}^{\text {plants }} \times \beta_{W_{i j}}^{\text {pollinators }}\right]=-4.86\right.$, $p=0.200)$. We therefore removed this term and re-fit the model. Dissimilarity then increased significantly with increasing turnover in the pollinator assemblage but did not vary significantly with turnover in the plant assemblage $\left(\beta_{W_{i j}}^{\text {plants }}=0.523, p=0.494\right.$; $\beta_{W_{i j}}^{\text {pollinators }}=4.32, p<0.001$; Fig. $\left.4 \mathrm{a}-\mathrm{b}\right)$. For pollinators' roles, dissimilarity was related to the interaction term for turnover in the plant and pollinator assemblages. This interaction was negative, while both main effects were positive $\left(\left[\beta_{W_{i j}}^{\text {plants }} \times \beta_{W_{i j}}^{\text {pollinators }}\right]=-7.88, p=0.012\right.$, $\beta_{W_{i j}}^{\text {plants }}=5.50, p=0.002$ and $\beta_{W_{i j}}^{\text {pollinators }}=4.90, p=0.003$, respectively). Unlike with plants, this means that simultaneous turnover in both assemblages could slow, or even reverse, the increase in role dissimilarity with plant and pollinator turnover (Fig. 4c-d).

\section{Comparisons within the same year}

Considering only comparisons between webs in the same year (i.e., within-year comparisons), role dissimilarity for plants still increased with increasing turnover in the pollinator assemblage but was not related to the amount of turnover in the plant assemblage or the interaction between the two turnover terms $\left(\beta_{W_{i j}}^{\text {plants }}=-2.26, p=0.661\right.$; $\beta_{W_{i j}}^{\text {pollinators }}=6.27, p=0.079 ;$ and $\left[\beta_{W_{i j}}^{\text {plants }} \times \beta_{W_{i j}}^{\text {pollinators }}\right]=-2.53, p=0.718$ for the regression including the interaction term and $\beta_{W_{i j}}^{\text {plants }}=-3.86, p=0.146 ; \beta_{W_{i j}}^{\text {pollinators }}=5.33, p=0.025$; Supplementary material Appendix A4, Fig. A5a-b). Dissimilarity in the roles of pollinators likewise was not related to the interaction term $\left(\left[\beta_{W_{i j}}^{\text {plants }} \times \beta_{W_{i j}}^{\text {pollinators }}\right]=-1.45, p=0.794\right)$. When we removed this term and re-fit the model, dissimilarity in pollinators' roles within a year was not related to turnover in the plant or pollinator assemblages $\left(\beta_{W_{i j}}^{\text {plants }}=-1.99\right.$, $p=0.334 ; \beta_{W_{i j}}^{\text {pollinators }}=3.26, p=0.071 ;$ Supplementary material Appendix A4, Fig. A5c-d).

\section{Comparisons between years, same month}

Considering only comparisons between webs describing the same month in different years (i.e., between-year comparisons), dissimilarity in plants' roles was related to the interaction term for turnover in the plant and pollinator assemblages. This interaction was negative, while both main effects were positive $\left(\beta_{W_{i j}}^{\text {plants }}=12.5, p=0.053 ; \beta_{W_{i j}}^{\text {pollinators }}=17.7, p=0.002\right.$; and $\left[\beta_{W_{i j}}^{\text {plants }} \times \beta_{W_{i j}}^{\text {pollinators }}\right]=-29.1, p=0.039 ;$ Supplementary material Appendix A4, Fig. A6a-b). Dissimilarity in pollinators' roles was not related to the interaction term $\left(\left[\beta_{W_{i j}}^{\text {plants }} \times \beta_{W_{i j}}^{\text {pollinators }}\right]=-12.7, p=0.271\right)$. After removing this term and re-fitting the model, dissimilarity in pollinators' roles increased with increasing turnover in the pollinator 
assemblage but was not related to turnover in the plant assemblage $\left(\beta_{W_{i j}}^{\text {plants }}=2.01, p=0.100\right.$; $\beta_{W_{i j}}^{\text {pollinators }}=2.95, p=0.035 ;$ Supplementary material Appendix A4, Fig. A6c-d).

\section{Discussion}

We found that both community composition and species' roles at Zackenberg changed over time. There were greater changes in the pollinator assemblage than in the plant assemblage between years, but both groups showed similar amounts of turnover within years. Likewise, the roles of species from both groups showed significant changes both within and between years. We found evidence that these trends were related, with plants' and pollinators' roles showing greater changes between webs with more different plant and pollinator assemblages. For pollinators, we also found that simultaneously high turnover in the plant and pollinator assemblages was associated with lower role dissimilarity than would be expected based on changes in the composition of either assemblage alone. Below, we will examine these findings in detail.

\section{Species turnover versus changes in species' roles}

Role dissimilarity for plants and pollinators generally increased with increasing turnover in the composition of the active plant-pollinator community. Turnover in the pollinator assemblage (i.e., the set of insects observed interacting with flowering plants) was related to the amount of change in the roles of both plants and pollinators. Turnover in the plant assemblage, however, was related to the amount of change in pollinators' roles but not the roles of plants. For plants, role dissimilarity always increased with increasing turnover. For pollinators, role dissimilarity could decrease with increasing turnover in one assemblage if turnover in the other assemblage was high enough. To better understand this result, consider the case of two network pairs: one with high turnover in both the plant and pollinator assemblages and one with high turnover in the pollinator assemblage but low turnover in the plant assemblage. Our analyses suggest that pollinators' roles would change less between the first pair of networks, with high turnover in both assemblages, than between the second pair of networks.

This negative interaction between turnover in the two assemblages suggests that simultaneous changes to the composition of both parts of a plant-pollinator network can apparently act to stabilise pollinators' roles between years. Such stabilisation could occur if the pollinators and plants that are most sporadically present (i.e., those that contribute most to turnover) tend to fill similar roles. It is possible that these sporadic species are rare and tend to interact with the most generalist partners available (Aizen et al. 2012); this could allow them to replace each other and hold the roles of more reliably resident pollinators constant. This is somewhat surprising as it suggests that newly-appeared species may tend to fill the "vacant" places of absent species with similar interaction patterns. This contrasts with an earlier suggestion that each species has a unique, constant role based on an earlier study of an oak gall miner-parasitoid network (Baker et al. 2015).

Based on earlier work at Zackenberg (Olesen et al. 2008), these results may arise because link formation in plant-pollinator networks appears to depend strongly on the degree and 
length of active period of the species involved: newly-arrived pollinators in particular tend to interact with the highest-degree plant with the longest flowering period (Olesen et al. 2008). This type of "preferential attachment" (Ponisio et al. 2017) could easily result in persistent species at Zackenberg tending to interact with an array of species which are only sporadically present, have few other interactions, and hence will contribute to the roles of the persistent species in very similar ways. When there is turnover in only one assemblage, our results suggest that the larger changes in species' roles over time may be due to some interaction rewiring, as in Ponisio et al. (2017). The differences between our results and those of Baker et al. (2015) may reflect structural differences between antagonistic and mutualistic systems. Host-parasitoid links may be more restricted by species' traits than plant-pollinator links and as such more consistent in the face of community turnover. The effects of turnover on the structure of, and species' roles in, different types of networks are likely to be a fruitful area of exploration for future studies.

Importantly, we observed stronger relationships between change in community composition and change in species' roles when comparing roles between years rather than within a single year. As many of the species at Zackenberg have short active periods (Høye et al. 2013, Wirta et al. 2016, Loboda et al. 2017), turnover within a year might be more likely to reflect the ebb and flow of floral resources and active pollinators through the summer than changes in which species are present at the site per se (Olesen et al. 2008). Interactions that can only occur during a short temporal window (i.e., when there is a small overlap in the active periods of plant and pollinator) are highly vulnerable to disruption (Burkle et al. 2013), and it is likely that many such interactions occur only sporadically at Zackenberg. Turnover of interactions above and beyond any change in community composition is well-known (Petanidou et al. 2008, Poisot et al. 2012, CaraDonna et al. 2017) and very likely to shape species' roles in this system. To facilitate future tests of this hypothesis, we encourage researchers compiling network data to consider this possibility and record species present at a site but not participating in pollination interactions. This additional detail would permit investigation of different components of turnover in interaction networks.

We also note that change in both the plant and pollinator assemblages were related to changes in the roles of both groups, depending on which set of comparisons we consider. Specifically, dissimilarity in plants' roles was related to turnover in the pollinator assemblage when all comparisons were considered and for comparisons within a year, and to turnover in both assemblages for comparisons between years. Dissimilarity in pollinators' roles was related to turnover in both assemblages when considering all comparisons, to neither assemblage for comparisons within a year, and to turnover in the pollinator assemblage for comparisons between years. The finding that turnover in an assemblage can be related to role dissimilarity for the same assemblage reinforces the importance of indirect interactions (e.g., between plants, mediated by their pollinators). Indirect interactions may shape networks through competition for pollination services (Kaiser-Bunbury et al. 2011), by the buffering the effects of changing abundances or extinctions (Kearns et al. 1998, Stouffer et al. 2014), or by the effects of network structure on species persistence (Memmott et al. 2004, Saavedra et al. 2011, Allesina and Tang 2012). Changes in the set of potential competitors in a community, as well as changes in the set of potential mutualists, should be taken into account when investigating the 
potential for change in an ecosystem service (in this case pollination) over time.

As well as turnover due to climate change or random fluctuations in the species present at Zackenberg, it is possible that some of the turnover we observe could be due to the fact that sampling in 1996-1997 and 2010-2011 was conducted by two different teams. The same sampling protocol was followed in all years in an effort to minimise variation in sampling effort, but nevertheless the 2010-2011 team spent approximately twice as many days sampling as the team in 1996-1997. However, this difference in sampling days will only apply to a fraction of our analyses: comparisons between webs in the same year or webs in different years from the same decade rely on data conducted by a single team and will not be affected. For comparisons between webs in different decades, it is impossible to tell whether the smaller number of pollinator species observed (similar numbers of plants were observed in all four years) was because the community was really smaller in these years, because of the reduced number of sampling days, or because the 2010-2011 team was more successful at identifying pollinators. In any case, as plants, insects, and interactions were collected at similar rates throughout the season in each year and numbers of both plants and insects appeared to saturate in each year (Supplementary material Appendix A1, Fig. A1), we do not believe that the different number of field days in 1996-1997 and 2010-2011 is behind the trends in turnover we observed.

\section{Changing roles in the Arctic}

It is always important to consider the context of an ecological network. In our study, the large changes in community composition between networks likely reflect the short flowering periods of many Arctic plants and short active periods of many Arctic arthropods (Høye et al. 2013, Rasmussen et al. 2013). These short active periods drive home the potential for phenological change to disrupt interactions through phenological uncoupling (Burkle et al. 2013, Høye et al. 2013, Gezon et al. 2016, Hua et al. 2016, Schmidt et al. 2016).

Phenological uncoupling can remove interactions even if the composition of the community is not changed (Tylianakis et al. 2010). Of course, it is possible that other factors we do not consider, in particular abundance (Kaiser-Bunbury et al. 2010, CaraDonna et al. 2017), may have greater effects on species interactions than phenological coupling; nevertheless, if a pair of species no longer has any temporal overlap then the species will not be able to interact regardless of other factors. Regardless of the relative strengths of effects of changes in abundance, phenological uncoupling, and community turnover, it is highly likely that all three factors are acting in concert to alter Arctic pollination networks. Unfortunately, we do not have estimates of abundance or phenology for some of the data used in these networks; we will therefore focus on community turnover as a potential cause of change to species' roles.

Among other contributions to turnover in the community, species' abundances may be important. Rarity has been shown to affect species' roles in previous studies, with rarely-observed generalist pollinators tending to appear more specialist than they truly are (Blüthgen et al. 2006). This finding suggests that rare species' roles may change more over time than those of abundant species because the full set of a rare species' interactions is less likely to be observed (Fort et al. 2016). Almost all abundant species are generalists which strongly implies that, had we observed more individuals of rare species, they would 
interact with more partners (Fort et al. 2016) and very likely have more consistent roles over time as a greater proportion of their interactions would remain constant between years. Rare species' roles also might truly vary more over time than those of abundant species if individuals vary strongly in their preferences for different interaction partners. Many pollinators that are generalists at the species level are much more specialised at the individual level (Pires et al. 2011). The smaller pool of individuals present in a rare species therefore makes it less likely that all possible interactions will occur in every given year. While testing these non-exclusive possibilities is outside the scope of the present study, it will be interesting to examine the relationships between abundance, community turnover, and change in roles in future work.

It is also important to place community turnover in the Arctic in the context of global climate change. Over the time period our dataset describes, the average summer near-surface air temperature at Zackenberg has increased at a rate of $1.3-1.8^{\circ} \mathrm{C}$ per decade, for a total increase of 1.95-2.7 (Høye et al. 2013, Mortensen et al. 2014). Snowmelt, meanwhile, advanced at a rate of 9.8-12.8 days per decade or 14.7-19.2 days over the course of our study (Høye et al. 2013, Mortensen et al. 2014). These environmental changes have been reflected in known phenological changes in both plants and pollinators (Høye et al. 2007, Høye and Forchhammer 2008, Høye et al. 2013, Schmidt et al. 2016). Combined with the increase in severe weather and other perturbations due to climate change (Hassol 2004, Adger et al. 2007, Steiner et al. 2015, Benestad et al. 2016), these phenological shifts imply that changes in which species are observed at a site and changes to species' roles may both increase as the Arctic continues to warm. Determining the amount of change caused by climate change versus random fluctuations is beyond the scope of the present study since the networks were observed at only four time points clustered fifteen years apart. Despite this uneven resolution, this set of temporally-replicated networks provides a valuable baseline for studies of the High Arctic plant-pollinator community. Such replicated networks are currently rare but very useful, especially where climate change is expected to be rapid. It would be valuable to revisit the Zackenberg site in the future to observe how further climate change has affected both the composition of the plant-pollinator community and the structure of the pollination network.

Extending the time series of networks at Zackenberg and combining these data with information on abundances and reproductive success may also allow future researchers to investigate the effects of changing motif frequencies on network stability and functioning. Theoretical work in unipartite networks suggests that motifs containing fewer links are more stable (Prill et al. 2005) and may be more frequently observed in ecological networks because of this stability (Prill et al. 2005, Borrelli et al. 2015). If specialist species are lost through future climate change then these sparse, stable motifs will become rarer. This could in turn lead the network as a whole to become less stable. As our results indicate that shifts between generalist and specialist positions are a major axis of variation in species' roles (Supplementary material Appendix A4, Fig. A4), such changes do seem likely in the future. More broadly, one next step for this line of research is to explicitly link different roles to the functioning and stability of networks. Such analyses would facilitate clearer interpretation of what changes in community composition and species roles mean for the network as a whole.

To conclude, in this study we have demonstrated both substantial community turnover 
and significant changes to species' roles in an Arctic plant-pollinator community. As the Arctic faces substantial pressure from climate change that are likely to lead to further changes in the pollinator (and plant) community in the future (Høye and Sikes 2017, Loboda et al. 2017), our results call for continued monitoring of pollination in plant-insect associations at high latitudes. As more data on species abundances, interactions, and responses to climate change become available, we will be able to untangle the causes of species turnover and their consequences for the functioning of pollination networks in this system. The tools and concepts presented in the current study will be ideal for use in such forthcoming work in the Arctic and elsewhere. 


\section{Declarations}

- Acknowledgements - We thank the staff at Zackenberg Research Station for access and logistical assistance in Greenland. Heidi Elberling and Jesper B. Mosbacher also collected data. Insects were identified by Elisabeth Stur and Torbjørn Ekrem (Chironomidae), Verner Michelsen (all other flies), Ole Karsholt (Lepidoptera), Gergely Várkonyi (wasps), Paul H. Williams (bumble bees). The Barcode of Life Data System (BOLD), Canada, sequenced all species to confirm identifications.

- Funding - Thanks to the Natural Sciences and Engineering Research Council of Canada (ARC), INTERACT (projects QUANTIC) under the European Community's Seventh Framework Programme (TR), the Academy of Finland (grant numbers 1276909 and 1285803 to TR), the Ella and Georg Ehrnrooth Foundation (TR), the Carlsberg Foundation (CR), the Danish Research Council (JMO), and a Marsden Fund grant (UOC-1101) and Rutherford Discovery Fellowship (DBS), both administered by the Royal Society of New Zealand, for financial support.

- Author contributions - JMO and CR collected field data. ARC, TR, CR, and DBS conceived of and designed the study. DBS wrote the motif-detection code. ARC carried out the statistical analyses. All authors helped draft the manuscript and gave final approval for publication.

- Conflicts of interest - No author has any conflict of interest.

\section{Supplementary material}

Appendix A1 - Accumulation curves

Appendix A2 - Tentatively dated observations: methods

Appendix A3 - Tentatively dated observations: results

Appendix A4 - Supplemental figures

Appendix A5 - Supplemental tables 


\section{References}

Adger, N. et al. 2007. Climate change 2007 - impacts, adaptation and vulnerability.. - In: Parry, M. L. et al. (eds.), Working Group II Contribution to the Intergovernmental Panel on Climate Change Fourth Assessment Report. Cambridge University Press, pp. 653-685.

Aizen, M. A. et al. 2012. Specialization and rarity predict nonrandom loss of interactions from mutualist networks. - Science 335: 1486-1489.

Allesina, S. and Tang, S. 2012. Stability criteria for complex ecosystems. - Nature 483: 205-208.

Anderson, M. J. 2001. A new method for non-parametric multivariate analysis of variance.. - Austral Ecol. 26: 32-46.

Baker, N. J. 2015. A quantitative exploration of the meso-scale structure of ecological networks. - Master's thesis, University of Canterbury.

Baker, N. J. et al. 2015. Species' roles in food webs show fidelity across a highly variable oak forest. - Ecography 38: 130-139.

Bascompte, J. and Melián, C. J. 2005. Simple trophic modules for complex food webs. Ecology 86: 2868-2873.

Benestad, R. E. et al. 2016. Climate change and projections for the Barents region: what is expected to change and what will stay the same?. - Environ. Res. Lett. 11: 054017.

Blüthgen, N. et al. 2006. Measuring specialization in species interaction networks.. - BMC Ecol. 6: 9 .

Borrelli, J. J. et al. 2015. Selection on stability across ecological scales. - Trends Ecol. Evol. 30: 417-425.

Burkle, L. A. et al. 2013. Plant-pollinator interactions over 120 years: loss of species, co-occurrence, and function. - Science 339: 1611-1615.

CaraDonna, P. J. et al. 2017. Interaction rewiring and the rapid turnover of plant-pollinator networks. - Ecol. Lett. 20: 385-394.

Carnicer, J. et al. 2009. The temporal dynamics of resource use by frugivorous birds: a network approach. - Ecology 90: 1958-1970.

Cirtwill, A. R. and Stouffer, D. B. 2015. Concomitant predation on parasites is highly variable but constrains the ways in which parasites contribute to food web structure. - J. Anim. Ecol. 84: 734-744.

Cuartas-Hernández, S. and Medel, R. 2015. Topology of plant - flower-visitor networks in a tropical mountain forest: insights on the role of altitudinal and temporal variation. PLoS ONE 10: e0141804. 
Diamond, J. M. 1969. Avifaunal equilibria and species turnover rates on the channel islands of California. - Proc. Natl. Acad. Sci. USA 64: 57-63.

Dobson, A. P. 2014. Yellowstone wolves and the forces that structure natural systems. PLoS Biol. 12: e1002025.

Emer, C. et al. 2016. Species roles in plant-pollinator communities are conserved across native and alien ranges. - Divers. Distrib. 22: 841-852.

Fenster, C. B. et al. 2004. Pollination syndromes and floral specialization. - Annu. Rev. Ecol. Evol. Sys. 35: 375-403.

Flenner, I. and Sahlén, G. 2008. Dragonfly community re-organisation in boreal forest lakes: rapid species turnover driven by climate change?. - Insect Cons. Divers. 1: 169-179.

Fort, H. et al. 2016. Abundance and generalisation in mutualistic networks: solving the chicken-and-egg dilemma. - Ecol. Lett. 19: 4-11.

Gezon, Z. J. et al. 2016. Phenological change in a spring ephemeral: implications for pollination and plant reproduction. - Glob. Chang. Biol. 22: 1779-1793.

Hanssen-Bauer, I. and Førland, E. J. 1998. Long-term trends in precipitation and temperature in the Norwegian Arctic: can they be explained by changes in atmospheric circulation patterns?. - Clim. Res. 10: 143-153.

Hassol, S. J. 2004. Impacts of a warming arctic - arctic climate impact assessment.. Cambridge University Press.

Høye, T. T. and Forchhammer, M. C. 2008. The influence of weather conditions on the activity of high-arctic arthropods inferred from long-term observations.. - BMC Ecol. 8: 8.

Høye, T. T. and Sikes, D. S. 2017. Arctic entomology in the 21st century. - Can. Entomol. 145: $125-130$.

Høye, T. T. et al. 2007. Rapid advancement of spring in the High Arctic. - Curr. Biol. 17: 449-451.

Høye, T. T. et al. 2013. Shorter flowering seasons and declining abundance of flower visitors in a warmer Arctic. - Nat. Clim. Chang. 3: 759-763.

Hua, F. et al. 2016. Community-wide changes in intertaxonomic temporal co-occurrence resulting from phenological shifts. - Glob. Chang. Biol. 22: 1746-1754.

Hubbell, S. P. 2009. Neutral theory and the theory of island biogeography. - In: Losos, J. B. and Ricklefs, R. E. (eds.), The theory of island biogeography revisited. Princeton University Press, pp. 264-292. 
Ives, A. R. and Carpenter, S. R. 2007. Stability and diversity of ecosystems.. - Science 317: $58-62$.

Kaiser-Bunbury, C. N. et al. 2010. The robustness of pollination networks to the loss of species and interactions: a quantitative approach incorporating pollinator behaviour. Ecol. Lett. 13: 442-452.

Kaiser-Bunbury, C. N. et al. 2011. The tolerance of island plant-pollinator networks to alien plants. - J. Ecol. 99: 202-213.

Kankaanpää, T. et al. 2018. Spatiotemporal snowmelt patterns within a high Arctic landscape - with implications for flora and fauna. - Arct. Antarc. Alp. Res. Accepted. DOI: $10.1080 / 15230430.2017 .1415624$.

Kearns, C. A. et al. 1998. Endangered mutualisms: the conservation of plant-pollinator interactions. - Annu. Rev. Ecol. Sys. 29: 83-112.

Knops, J. M. H. et al. 1999. Effects of plant species richness on invasion dynamics, disease outbreaks, insect abundances and diversity. - Ecol. Lett. 2: 286-293.

Kondoh, M. 2008. Building trophic modules into a persistent food web. - Proc. Natl. Acad. Sci. USA 105: 16631-16635.

Kuznetsova, A. et al. 2014. lmerTest: Tests for random and fixed effects for linear mixed effect models (lmer objects of lme4 package). - R package version 2.0-11 ed.

Loboda, S. et al. 2017. Declining diversity and abundance of High Arctic fly assemblages over two decades of rapid climate warming. - Ecography 40: 001-012.

MacArthur, R. H. and Wilson, E. O. 1967. The Theory of Island Biogeography.. Princeton University Press, princeton ed.

Memmott, J. et al. 2004. Tolerance of pollination networks to species extinctions. - Proc. R. Soc. Lond. B 271: 2605-2611.

Milo, R. et al. 2002. Network motifs: simple building blocks of complex networks. - Science 298: 824-827.

Milo, R. et al. 2004. Superfamilies of evolved and designed networks. - Science 303: $1538-1542$

Mitchell, R. J. et al. 2009. New frontiers in competition for pollination. - Ann. Bot. 103: 1403-1413.

Mortensen, L. O. et al. 2014. Temporal trends and variability in a high-arctic ecosystem in Greenland: multidimensional analyses of limnic and terrestrial ecosystems. - Polar Biol. 37: 1073-1082.

Motten, A. F. 1986. Pollination ecology of the spring wildflower community of a temperate deciduous forest. - Ecol. Monogr. 56: 21-42. 
Nuñez, M. A. et al. 2010. Population, community and ecosystem effects of exotic herbivores: a growing global concern. - Biol. Invasions 12: 297-301.

Oksanen, A. J. et al. 2012. vegan: Community Ecology Package. - R package version 2.2-0 ed.

Olesen, J. M. et al. 2008. Temporal dynamics in a pollination network. - Ecology 89: $1573-1582$.

Olesen, J. M. et al. 2011. Strong, long-term temporal dynamics of an ecological network. PLoS ONE 6: e26455.

Ollerton, J. et al. 2009. A global test of the pollination syndrome hypothesis. - Ann. Bot. 103: $1471-1480$.

Petanidou, T. et al. 2008. Long-term observation of a pollination network: fluctuation in species and interactions, relative invariance of network structure and implications for estimates of specialization. - Ecol. Lett. 11: 564-575.

Pires, M. M. et al. 2011. Do food web models reproduce the structure of mutualistic networks?. - PLoS ONE 6: e27280.

Poisot, T. et al. 2012. The dissimilarity of species interaction networks. - Ecol. Lett. 15: $1353-1361$.

Ponisio, L. C. et al. 2017. Opportunistic attachment assembles plant-pollinator networks. Ecol. Lett. 20: 1261-1272.

Prill, R. J. et al. 2005. Dynamic properties of network motifs contribute to biological network organization. - PLoS Biol. 3: e343.

R Core Team 2014. R: A language and environment for statistical computing.. - R Foundation for Statistical Computing.

Rasmussen, C. et al. 2013. Strong impact of temporal resolution on the structure of an ecological network. - PLoS ONE 8: e81694.

Saavedra, S. et al. 2011. Strong contributors to network persistence are the most vulnerable to extinction. - Nature 478: 233-235.

Schmidt, N. M. et al. 2016. An ecological function in crisis? The temporal overlap between plant flowering and pollinator function shrinks as the Arctic warms. - Ecography 39: 1-3.

Simanonok, M. P. and Burkle, L. A. 2014. Partitioning interaction turnover among alpine pollination networks: spatial, temporal, and environmental patterns. - Ecosphere 5: $\operatorname{art149.}$

Simberloff, D. S. and Wilson, E. O. 1969. Experimental zoogeography of islands: the colonization of empty islands. - Ecology 50: 278-296. 
Steiner, N. et al. 2015. Observed trends and climate projections affecting marine ecosystems in the Canadian Arctic. - Environ. Rev. 23: 191-239.

Stouffer, D. B. and Bascompte, J. 2010. Understanding food-web persistence from local to global scales. - Ecol. Lett. 13: 154-161.

Stouffer, D. B. et al. 2007. Evidence for the existence of a robust pattern of prey selection in food webs. - Proc. R. Soc. B 274: 1931-1940.

Stouffer, D. B. et al. 2012. Evolutionary conservation of species' roles in food webs. Science 335: 1489-1492.

Stouffer, D. B. et al. 2014. How exotic plants integrate into pollination networks. - J. Ecol. 102: $1442-1450$.

Tylianakis, J. M. et al. 2010. Conservation of species interaction networks. - Biol. Conserv. 143: $2270-2279$.

Vázquez, D. P. et al. 2009. Uniting pattern and process in plant-animal mutualistic networks: a review. - Ann. Bot. 103: 1445-1457.

Vizentin-Bugoni, J. et al. 2014. Processes entangling interactions in communities: forbidden links are more important than abundance in a hummingbird-plant network. Proc. R. Soc. B 281: 20132397.

Waser, N. M. et al. 1996. Generalization in pollination systems, and why it matters. Ecology 77: 1043-1060.

Weinstein, B. G. and Graham, C. H. 2017. Persistent bill and corolla matching despite shifting temporal resources in tropical hummingbird-plant interactions. - Ecol. Lett. 20: $326-335$.

Whittaker, R. H. 1972. Evolution and measurement of species diversity. - Taxon 21: $213-251$.

Wirta, H. et al. 2016. Establishing a community-wide DNA barcode library as a new tool for arctic research. - Mol. Ecol. Res. 16: 809-822. 


\section{Tables}

Table 1: Plants and pollinators in different year or year-month combinations had significantly different median roles, as indicated by a series of PERMANOVA tests. Here we give, for each test, the mean Bray-Curtis dissimilarity between roles of species in the same group ('Within') or in different groups ('Between'), for plants and pollinators. When comparing species' roles in yearly networks, years were used as groups. When comparing species' roles in monthly networks, we ran PERMANOVAs using either years (P1) or years, months, and year-month combinations (P2) as groups. In all cases, we give the mean and standard deviation for each dissimilarity, as well as the pseudo- $F$ statistic and $p$-value from the corresponding PERMANOVA. As the conclusions were identical for PERMANOVAs comparing species' roles in monthly networks across years in tests $\mathrm{P} 1$ and $\mathrm{P} 2$, we discuss only the results for P1 in the main text.

\begin{tabular}{llllllr}
\hline Network & Group & Assemblage & Within & Between & F & p \\
\hline Yearly & Year & Plants & 0.397 & 0.431 & 5.76 & $<0.001$ \\
Monthly & Year (P1) & Plants & 0.528 & 0.549 & 3.31 & 0.001 \\
Monthly & Year (P2) & Plants & 0.527 & 0.549 & 2.89 & 0.001 \\
Monthly & Month & Plants & 0.494 & 0.573 & 6.62 & $<0.001$ \\
Monthly & Year + month & Plants & 0.451 & 0.553 & 3.52 & 0.001 \\
\hline Yearly & Year & Pollinators & 0.388 & 0.422 & 13.6 & $<0.001$ \\
Monthly & Year (P1) & Pollinators & 0.504 & 0.522 & 9.35 & $<0.001$ \\
Monthly & Year (P2) & Pollinators & 0.504 & 0.522 & 4.16 & $<0.001$ \\
Monthly & Month & Pollinators & 0.487 & 0.535 & 11.2 & $<0.001$ \\
Monthly & Year + month & Pollinators & 0.451 & 0.524 & 4.16 & $<0.001$ \\
\hline
\end{tabular}


Table 2: Coefficients (with standard errors in parentheses) and $p$-values for regressions of role similarity against turnover in the plant assemblage, pollinator assemblage, and the interaction between the two (full model). When the interaction term was not significant, we removed it and re-fit the regression (reduced model).

\begin{tabular}{|c|c|c|c|c|c|c|}
\hline \multicolumn{7}{|c|}{ Dissimilarity in plants' roles } \\
\hline & \multicolumn{2}{|c|}{ All comparisons } & \multicolumn{2}{|c|}{ Within-year only } & \multicolumn{2}{|c|}{ Between-year only } \\
\hline \multicolumn{7}{|c|}{ Full model } \\
\hline \multirow{3}{*}{$\begin{array}{l}\beta_{W_{i j}}^{\text {plants }} \\
\beta_{W_{i j} \text { pollinators }}^{\text {plants }} \times \beta_{W_{i j}}^{\text {pollinators }} \\
\beta_{W_{i j}}^{\text {plant }}\end{array}$} & $3.00(2.05)$ & 0.152 & $-2.26(5.10)$ & 0.661 & $12.5(6.23)$ & 0.053 \\
\hline & $6.48(1.91)$ & 0.002 & $6.27(3.46)$ & 0.079 & $17.7(5.33)$ & 0.002 \\
\hline & $-4.86(3.71)$ & 0.200 & $-2.53(6.94)$ & 0.718 & $-29.1(13.5)$ & 0.039 \\
\hline \multicolumn{7}{|c|}{ Reduced model } \\
\hline \multirow{2}{*}{$\begin{array}{l}\beta_{W_{i j} \text { plants }} \\
\beta_{W_{i j}^{\text {pollinators }}}^{\text {pols }}\end{array}$} & $0.523(0.756)$ & 0.494 & $-3.86(2.59)$ & 0.146 & \multirow{2}{*}{\multicolumn{2}{|c|}{$\begin{array}{l}\text { NA } \\
\text { NA }\end{array}$}} \\
\hline & $4.32(0.926)$ & $<0.001$ & $5.33(2.27)$ & 0.025 & & \\
\hline \multicolumn{7}{|c|}{ Dissimilarity in pollinators' roles } \\
\hline \multicolumn{7}{|c|}{ Full model } \\
\hline \multirow{3}{*}{$\begin{array}{l}\beta_{W_{i j} \text { plants }} \\
\beta_{W_{i j}}^{\text {pollinators }} \\
\beta_{W_{i j}}^{\text {plants }} \times \beta_{W_{i j}}^{\text {pollinators }} \\
\end{array}$} & $5.50(1.68)$ & 0.002 & $-1.14(3.84)$ & 0.768 & $7.45(5.07)$ & 0.146 \\
\hline & $4.90(1.60)$ & 0.003 & $3.84(2.85)$ & 0.181 & $7.38(4.26)$ & 0.086 \\
\hline & $-7.88(3.08)$ & 0.012 & $-1.45(5.53)$ & 0.794 & $-12.7(11.4)$ & 0.271 \\
\hline \multicolumn{7}{|c|}{ Reduced model } \\
\hline \multirow{2}{*}{$\begin{array}{l}\beta_{W_{i j} \text { plants }} \\
\beta_{W_{i j}}^{\text {pollinators }}\end{array}$} & NA & & $-1.99(2.05)$ & 0.334 & $2.01(1.21)$ & 0.100 \\
\hline & NA & & $3.26(1.78)$ & 0.071 & $2.95(1.37)$ & 0.035 \\
\hline
\end{tabular}




\section{Figure Captions}

Figure 1: In this study, we use motifs (unique patterns of 2-6 interacting species that can be understood as the building blocks of networks) to describe species roles. In panel (a) we show a small network made up of pollinators (white circles A-C) and plants (black circles $\mathrm{D}-\mathrm{F}$ ). This network can be broken down into its component motifs (shown in panel b). Note that each motif contains at least two unique positions (numbered). Here we show all motifs of size 2-4. The full set of 2-6 species motifs is given in Supplementary material Appendix A4, Fig. A2. In panel (c), we show each instance of each motif in the network from panel (a). Decomposing the network into its component motifs allows us to describe species roles. Panel (d) shows the roles of species A-F: each role is the vector of frequencies with which the species appears in each position in each motif (shown as columns). The role of species A (defined as the vector $[3,0,3,0, \ldots]$ ) indicates that $\mathrm{A}$ appears three times in position 1 , never in position 2 , three times in position 3 , etc. Note that plants and pollinators can never occupy the same positions (i.e., species A can never appear in even-numbered positions and species B can never appear in odd-numbered positions).

(a) Network
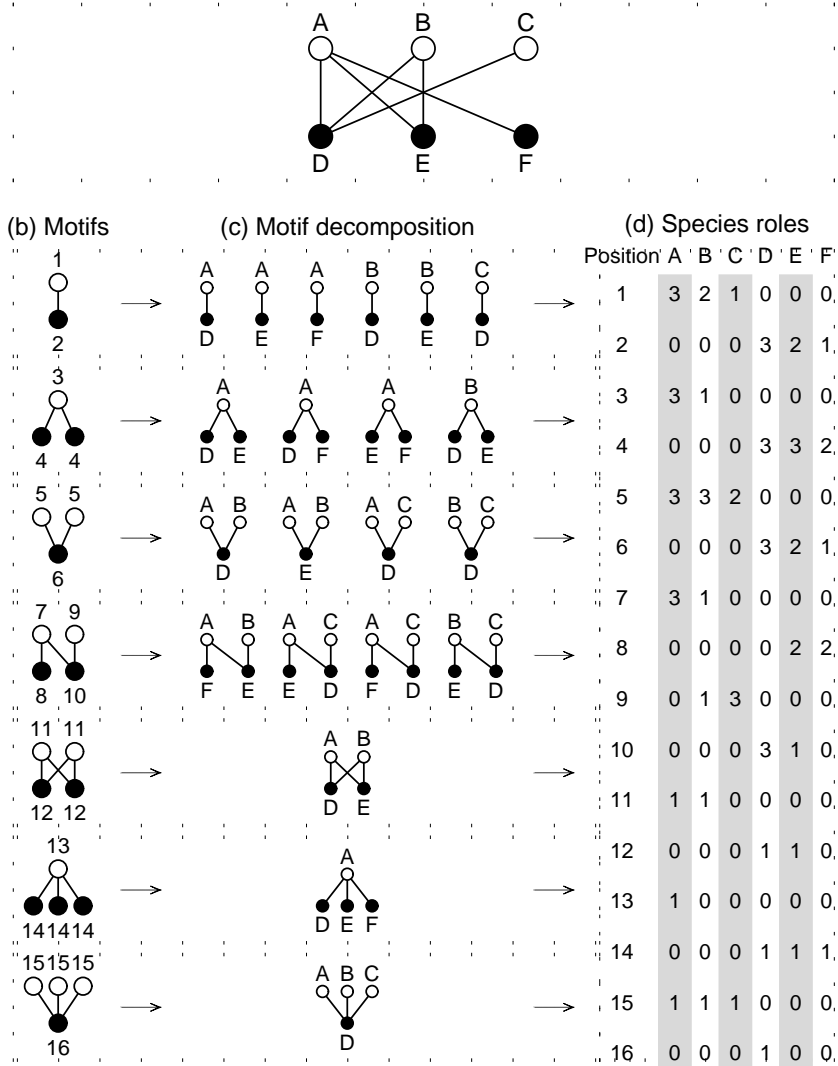
Figure 2: After calculating species' roles in each network, we can then compare these roles. In this study, we were particularly interested in whether the dissimilarity between species' roles was related to the amount of turnover between networks. In panel (a), we show three networks. Network i is the same network as that given in Fig. 1a. Network ii is very similar to network $\mathrm{i}$, except that pollinator $\mathrm{C}$ was not observed and a new pollinator, $\mathrm{Z}$, has been observed. There was therefore very little turnover between networks i and ii. In network iii, only one plant and one pollinator from network i were observed. This indicates high turnover between networks $\mathrm{i}$ and iii. In panel (b), we show how the role of pollinator A differed between networks. Specifically, we give the frequency of each position in the 2- to 4-species motifs described in Fig. 1b, normalised by the total number of times species A appears in positions 1-16 in a network. There was no difference in A's role between networks i and ii (black and dark grey) but substantial change between networks i and iii (black and light grey). Below panel (b) we show each position in its motif context. Positions that can be occupied by pollinators are coloured white while positions that can be occupied by plants are in grey.

(a) Networks

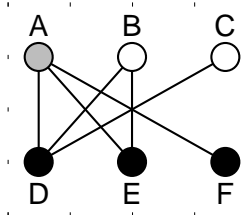

Network i

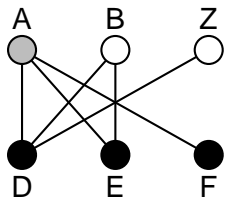

Network ii

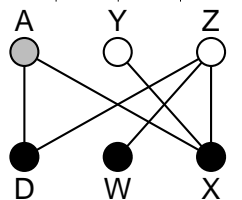

Network iii

(b) Roles of species A in all networks
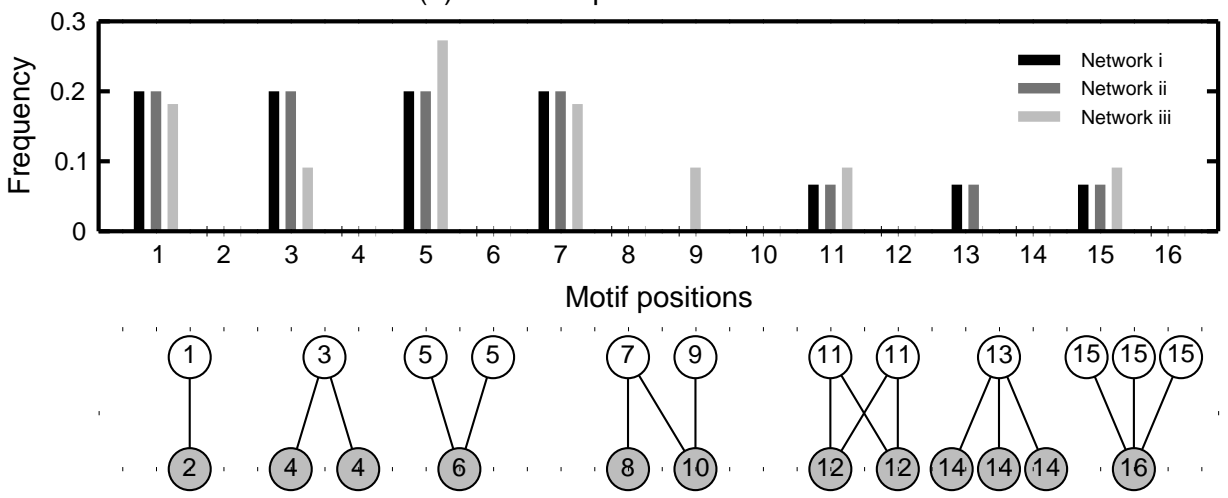
Figure 3: The median roles of plants and their insect pollinators differed between years and months. Here we show the median roles of plants and pollinators in each network, plotted against two NMDS axes. We conducted separate NMDS analyses for plants and pollinators; stress values for these NMDS were 0.080 and 0.091, respectively. a-b) The median roles of both plants and pollinators in yearly plant-pollinator networks differed significantly between years based on PERMANOVAs of role dissimilarity against year (Table 1). Dispersion about these median roles did not vary between years. For both plants and pollinators, the median role in the 2011 web was the most distinct from other median roles. c-h) The median roles of plants and pollinators in the monthly networks also varied significantly between years, months, and month-year combinations based on PERMANOVAs of role dissimilarity against year and year, month, and month-year combinations (Table 1). Dispersion about these median roles varied between month-year combinations for the roles of plants but not those of pollinators. For both plants and pollinators, median roles in the June and August webs differed between years while the median roles in the July webs were similar in all years. For an interpretation of these axes, see Supplementary material Appendix A4, Fig. A4. Note that the NMDS analyses are for visualisation purposes only; all statistical conclusions were based upon the PERMANOVA tests.

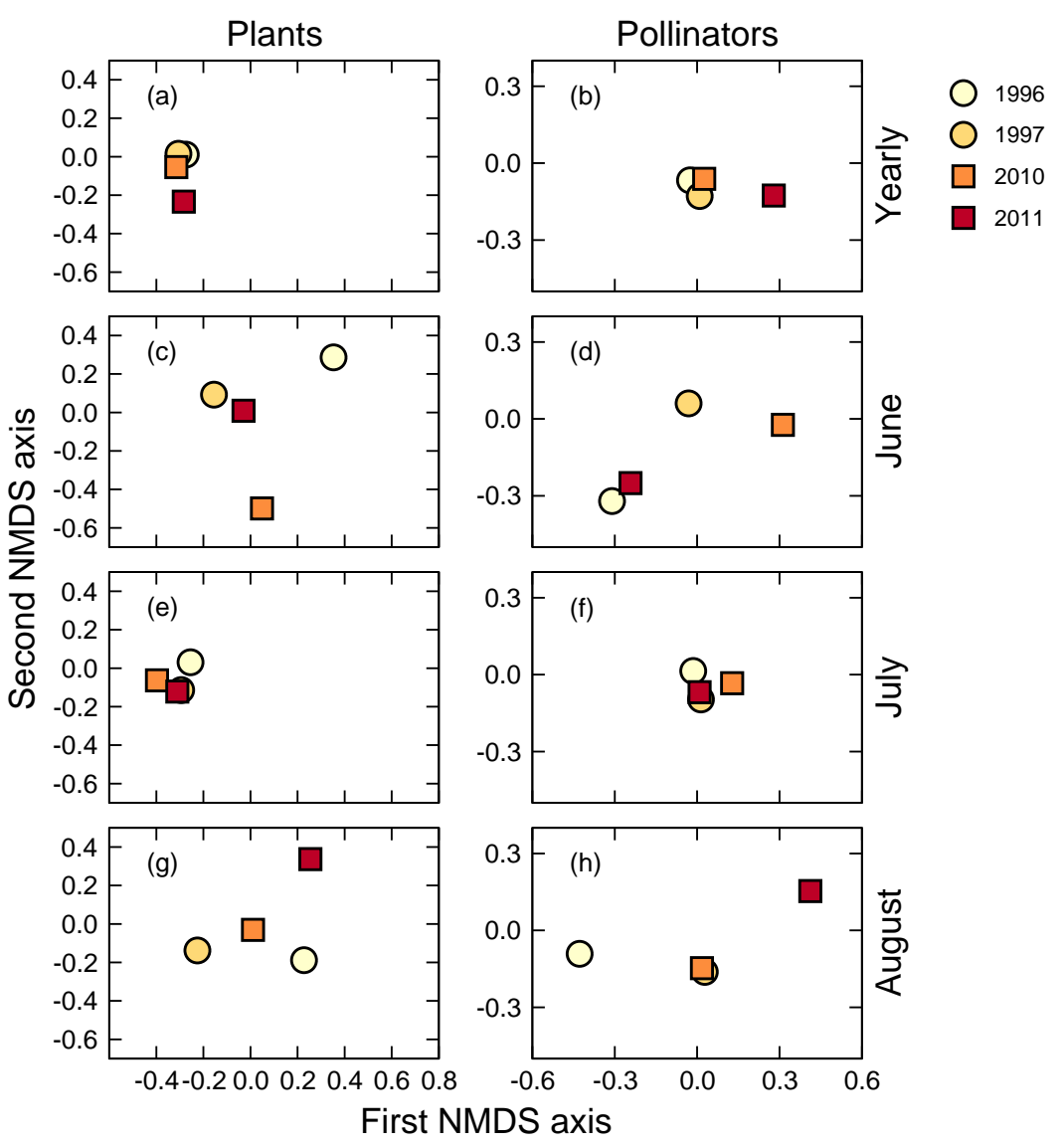


Figure 4: When all comparisons were taken together, dissimilarity in the roles of plants, but not pollinators, was related to the amount of turnover in both assemblages. a-b) Dissimilarity in plants' roles always increased with increasing turnover in the pollinator assemblage, although the shape of the relationship changed slightly depending on the amount of turnover in the plant assemblage. The interaction term between plant and pollinator turnover was not significant and was removed from the model. c-d) Dissimilarity in pollinators' roles was also affected by turnover in the pollinator assemblage, but in this case a significant negative interaction between the effects of plant and pollinator turnover complicated the relationship. Role dissimilarity increased with increasing turnover in the pollinator assemblage when plant turnover was low to moderate, but decreased with increasing turnover in the pollinator assemblage when the amount of plant turnover was high. In panels (a) and (c) we show the observed relationship between role dissimilarity and pollinator turnover, while in panels (b) and (d) we show predictions based on the fixed effects of equation (1) (i.e., excluding random effects of species). We show predictions for the minimum and maximum observed plant turnover, as well as moderate values of turnover between the two extremes. Only predictions for combinations of plant and pollinator turnover observed in our data are depicted. Both observed data and prediction lines are coloured along the same scale, according to plant turnover.
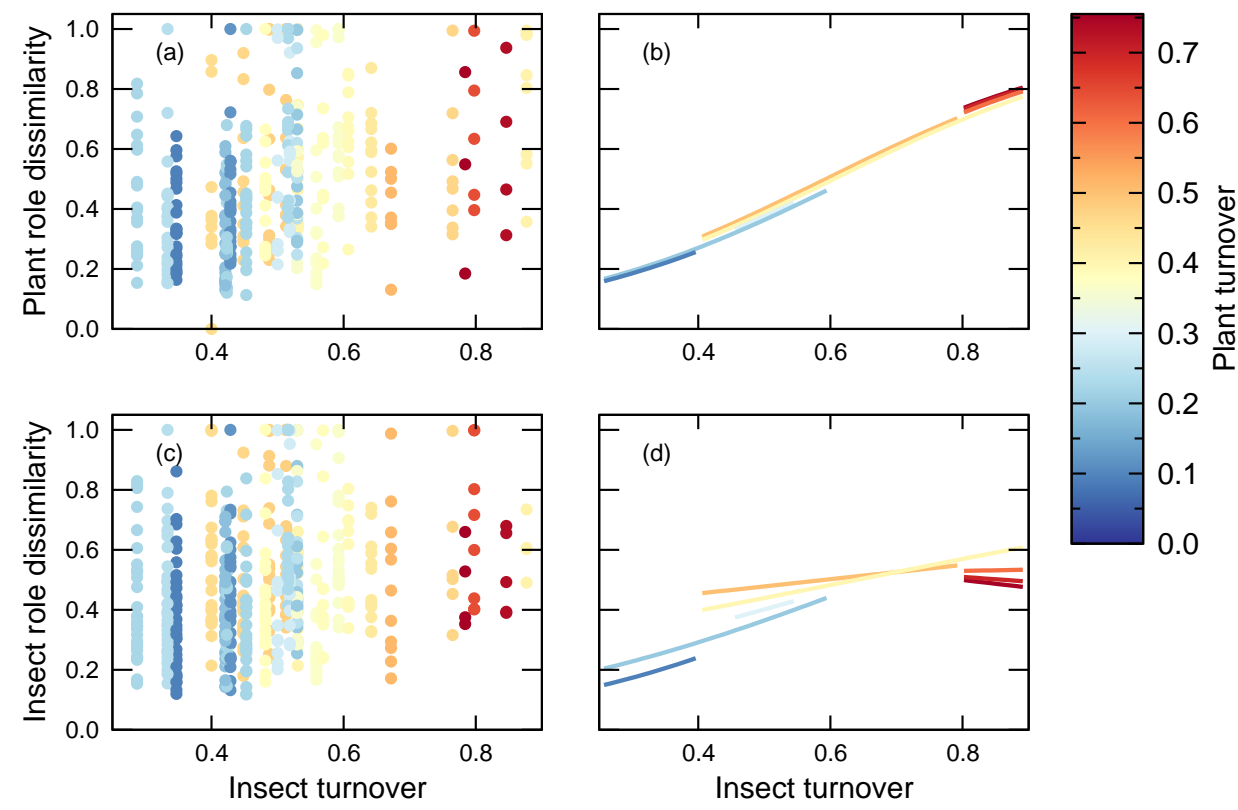


\title{
Between-year changes in community composition shape species' roles in an Arctic plant-pollinator network: Supplemental material
}

\author{
Alyssa R. Cirtwill ${ }^{1,2 \dagger}$, Tomas Roslin ${ }^{3,4}$, Claus Rasmussen ${ }^{5}$, Jens Mogens \\ Olesen $^{6}$, Daniel B. Stouffer ${ }^{1}$ \\ ${ }^{1}$ Centre for Integrative Ecology \\ School of Biological Sciences, University of Canterbury \\ Private Bag 4800, Christchurch 8140, New Zealand \\ ${ }^{2}$ Present address: Department of Physics, Chemistry, and Biology (IFM) \\ Linköping University \\ 58183 Linköping, Sweden \\ ${ }^{3}$ Department of Ecology \\ P.O. Box 7044, Swedish University of Agricultural Sciences \\ SE-750 07 Uppsala, Sweden \\ 4 Spatial Foodweb Ecology Group \\ Department of Agricultural Sciences \\ PO Box 27 (Latokartanonkaari 5) \\ FI-00014 University of Helsinki, Finland \\ ${ }^{5}$ Department of Bioscience, Aarhus University \\ Ole Worms Allé 1, DK-8000 Aarhus C, Denmark \\ ${ }^{6}$ Department of Bioscience, Aarhus University \\ Ny Munkegade 114, DK-8000 Aarhus C, Denmark \\ $\dagger$ corresponding author \\ e-mail: alyssa.cirtwill@gmail.com, tel: +64 33667001 x7654
}




\section{Appendix A1 - Accumulation curves}

Figure A1: Accumulation of observed plants, pollinators, and interactions was similar in all years of our dataset, despite the reduced number of sampling days in 1996 and 1997. Based on this, we conclude that number of sampling days did not greatly affect our results.
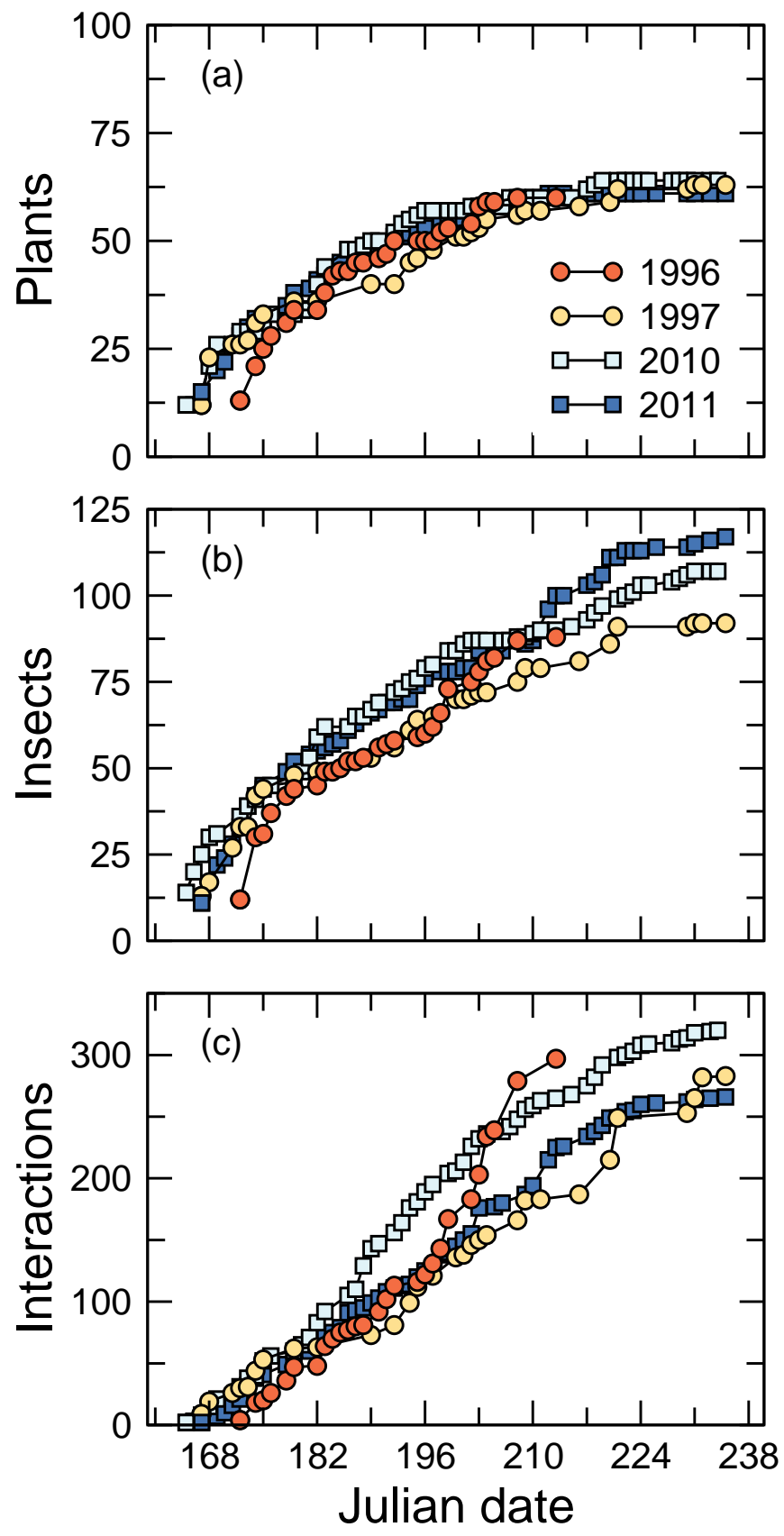


\section{Appendix A2 - Tentatively dated observations: methods}

There were 94 interactions in our dataset which could not be ascribed to a definite date.

Of these, 41 were observed in 1996 and the remaining 53 were observed in 1997. The interactions involve five insect species visiting 15 plant species. Boloria chariclea visited all 15 plants, Colias hecla visited four plant species, Limnophyes brachytomus visited three, and Paraphaenocladius impensus and Syngrapha parilis each visited one. In addition to visiting the most plant species, Boloria chariclea was observed far more often than any of the other insects with tentatively-dated observations (79 of the 94 such observations).

Each interaction is associated with a range of possible dates where the plant had been observed flowering and the insect had been observed at the site. Within this range, we used the earliest date that was not associated with a definitively-labelled interaction as the bestguess date for the interaction. This date was used to include the interaction in the monthly networks described in the main text. Because of the uncertainty regarding these dates, we repeated our analyses using two other methods of assigning these interactions. First, we excluded these interactions from the monthly networks entirely. As each interaction was definitively associated with a particular year, however, we included the interactions in the yearly networks. This method underestimated the number of interactions in the 1996 and 1997 monthly networks but presented no risk of assigning an interaction incorrectly. Second, we included the interaction in all networks describing any part of the range of potential dates. This included the yearly networks, as in the other methods, and any relevant monthly networks. This method over-estimates the number of interactions in the 1996 and 1997 monthly networks, but does not exclude any of the pollination interactions that occurred. These three methods of assembling the monthly networks cover a range of conservatism and all have different attendant biases. As described below, all results were qualitatively identical regardless of the method use. 


\section{Appendix A3 - Tentatively dated observations: results}

\section{Turnover}

We observed similar levels of turnover between monthly networks regardless of the method used to account for tentatively-dated observations.

Table A1: Turnover at Zackenberg between monthly webs describing different months in the same year (measured using Whittaker's beta diversity index) when tentatively-dated observations were included in the yearly networks only.

\begin{tabular}{|c|c|c|c|c|}
\hline Year & \multicolumn{2}{|c|}{ Months } & Pollinator turnover & Plant turnover \\
\hline 1996 & June & July & 0.513 & 0.463 \\
\hline 1996 & June & August & 0.783 & 0.727 \\
\hline 1996 & July & August & 0.642 & 0.538 \\
\hline 1997 & June & July & 0.559 & 0.368 \\
\hline 1997 & June & August & 0.672 & 0.514 \\
\hline 1997 & July & August & 0.287 & 0.224 \\
\hline 2010 & June & July & 0.448 & 0.463 \\
\hline 2010 & June & August & 0.846 & 0.733 \\
\hline 2010 & July & August & 0.531 & 0.404 \\
\hline 2011 & June & July & 0.487 & 0.476 \\
\hline 2011 & June & August & 0.797 & 0.643 \\
\hline 2011 & July & August & 0.592 & 0.364 \\
\hline
\end{tabular}

Table A2: Turnover at Zackenberg between monthly webs describing different months in the same year (measured using Whittaker's beta diversity index) when tentatively-dated observations were included in any network including part of the range of tentative dates.

\begin{tabular}{|c|c|c|c|c|}
\hline Year & \multicolumn{2}{|c|}{ Months } & Pollinator turnover & Plant turnover \\
\hline 1996 & June & July & 0.513 & 0.319 \\
\hline 1996 & June & August & 0.692 & 0.273 \\
\hline 1996 & July & August & 0.594 & 0.304 \\
\hline 1997 & June & July & 0.536 & 0.217 \\
\hline 1997 & June & August & 0.672 & 0.349 \\
\hline 1997 & July & August & 0.273 & 0.176 \\
\hline 2010 & June & July & 0.448 & 0.463 \\
\hline 2010 & June & August & 0.846 & 0.733 \\
\hline 2010 & July & August & 0.531 & 0.404 \\
\hline 2011 & June & July & 0.487 & 0.476 \\
\hline 2011 & June & August & 0.797 & 0.643 \\
\hline 2011 & July & August & 0.592 & 0.364 \\
\hline
\end{tabular}


Table A3: Turnover at Zackenberg between monthly webs describing the same month in different years (measured using Whittaker's beta diversity index) when tentatively-dated observations were included in the yearly networks only.

\begin{tabular}{lllll}
\hline Month & \multicolumn{2}{c}{ Years } & Pollinator turnover & Plant turnover \\
\hline June & 1996 & 1997 & 0.500 & 0.280 \\
June & 1996 & 2010 & 0.529 & 0.250 \\
June & 1996 & 2011 & 0.529 & 0.360 \\
June & 1997 & 2010 & 0.529 & 0.200 \\
June & 1997 & 2011 & 0.569 & 0.385 \\
June & 2010 & 2011 & 0.519 & 0.280 \\
July & 1996 & 1997 & 0.347 & 0.111 \\
July & 1996 & 2010 & 0.421 & 0.207 \\
July & 1996 & 2011 & 0.429 & 0.103 \\
July & 1997 & 2010 & 0.423 & 0.222 \\
July & 1997 & 2011 & 0.453 & 0.222 \\
July & 2010 & 2011 & 0.333 & 0.241 \\
August & 1996 & 1997 & 0.607 & 0.412 \\
August & 1996 & 2010 & 0.765 & 0.429 \\
August & 1996 & 2011 & 0.877 & 0.360 \\
August & 1997 & 2010 & 0.481 & 0.381 \\
August & 1997 & 2011 & 0.516 & 0.231 \\
August & 2010 & 2011 & 0.400 & 0.455 \\
\hline
\end{tabular}


Table A4: Turnover at Zackenberg between monthly webs describing the same month in different years (measured using Whittaker's beta diversity index) when tentatively-dated observations were included in any network including part of the range of tentative dates.

\begin{tabular}{lllll}
\hline Month & \multicolumn{2}{c}{ Years } & Pollinator turnover & Plant turnover \\
\hline June & 1996 & 1997 & 0.500 & 0.222 \\
June & 1996 & 2010 & 0.529 & 0.310 \\
June & 1996 & 2011 & 0.529 & 0.400 \\
June & 1997 & 2010 & 0.529 & 0.226 \\
June & 1997 & 2011 & 0.569 & 0.438 \\
June & 2010 & 2011 & 0.519 & 0.280 \\
July & 1996 & 1997 & 0.333 & 0.053 \\
July & 1996 & 2010 & 0.421 & 0.186 \\
July & 1996 & 2011 & 0.429 & 0.119 \\
July & 1997 & 2010 & 0.410 & 0.214 \\
July & 1997 & 2011 & 0.438 & 0.179 \\
July & 2010 & 2011 & 0.333 & 0.241 \\
August & 1996 & 1997 & 0.552 & 0.25 \\
August & 1996 & 2010 & 0.698 & 0.412 \\
August & 1996 & 2011 & 0.821 & 0.355 \\
August & 1997 & 2010 & 0.481 & 0.381 \\
August & 1997 & 2011 & 0.516 & 0.231 \\
August & 2010 & 2011 & 0.400 & 0.455 \\
\hline
\end{tabular}

\section{Change in species' roles}

\section{Tentatively-dated observations in yearly webs only}

When tentatively-dated observations were not included in the monthly webs, plants' roles in monthly networks varied between years $\left(F_{1,227}=2.37, p=0.012\right)$. When month and monthyear combination were added to the PERMANOVA, plants' roles varied between years, months, and month-year combinations $\left(F_{1,223}=2.52, p=0.013 ; F_{2,223}=6.83, p<0.001\right.$; and $F_{2,223}=2.15, p=0.010$, respectively). Dispersion of plants' roles was significantly different both between years $\left(F_{3,225}=3.32, p=0.021\right)$ and month-year combinations $\left(F_{11,217}=3.25\right.$, $p<0.001)$.

Meanwhile, insects' roles in monthly networks varied between years $\left(F_{1,455}=8.51, p<0.001\right)$. When month and month-year combination were added to the PERMANOVA, insects' roles varied between years, months, and month-year combinations $\left(F_{1,451}=9.00, p<0.001 ; F_{2,451}=12.1\right.$, $p<0.001$; and $F_{2,451}=3.09, p=0.001$, respectively). Dispersion of insects' roles was significantly different between years $\left(F_{3,453}=3.37, p=0.018\right)$ but not between month-year combinations $\left(F_{11,445}=1.04, p=0.414\right)$.

\section{Tentatively-dated observations in all webs in range}

When tentatively-dated observations were included in all webs covering any of the range of potential dates, plants' roles in monthly webs again varied between years $\left(F_{1,247}=6.00\right.$, $p<0.001)$. When month and month-year combination were added to the PERMANOVA, 
plants' roles varied between years, months, and month-year combinations $\left(F_{1,243}=6.38, p<0.001\right.$; $F_{2,243}=5.06, p<0.001$; and $F_{2,243}=4.87, p<0.001$, respectively). Dispersion of plants' roles was significantly different between years $\left(F_{3,245}=4.46, p=0.005\right)$ and month-year combinations $\left(F_{11,237}=3.46, p<0.001\right)$. Regardless of the method used to account for the tentatively-dated observations, our conclusions about change to plants' roles over time remained the same.

Insects' roles in monthly webs, meanwhile, again varied between years $\left(F_{1,458}=14.4\right.$, $p<0.001)$. When month and month-year combination were added to the PERMANOVA, insects' roles varied between years, months, and month-year combinations $\left(F_{1,454}=15.1\right.$, $p<0.001 ; F_{2,454}=8.28, p<0.001$; and $F_{2,454}=5.30, p<0.001$, respectively). Dispersion of insects' roles was significantly different between years $\left(F_{3,456}=3.152, p=0.015\right)$ but not monthyear combinations $\left(F_{11,448}=0.764, p=0.676\right)$. As with plants' roles, our conclusions about change to insects' roles over time were not affected by the method used to account for the tentatively-dated observations.

\section{Turnover and amount of change in species' roles}

\section{Tentatively-dated observations in yearly webs only}

When tentatively-dated observations were not included in the monthly webs, the amount of dissimilarity in plants' roles increased with increasing turnover in the insect community but was not affected by turnover in the plant community or the interaction between the two turnover terms $\left(\beta_{W_{i j}}^{\text {plants }}=2.01, p=0.328 ; \beta_{W_{i j}}^{\text {pollinators }}=5.06, p=0.010 ;\right.$ and $\beta_{W_{i j}}^{\text {plants }} \times \beta_{W_{i j}}^{\text {pollinators }}=-$ $3.21, p=0.375$ for the regression including the interaction term and $\beta_{W_{i j}}^{\text {plants }}=0.329, p=0.664$; $\beta_{W_{i j}}^{\text {pollinators }}=3.66, p<0.001$ when the interaction term was removed). For insects, dissimilarity between roles in different monthly networks increased strongly with turnover in both the plant and insect communities $\left(\beta_{W_{i j}}^{\text {plants }}=5.51, p=0.001\right.$ and $\beta_{W_{i j}}^{\text {pollinators }}=4.89, p=0.003$, respectively) but decreased with the interaction term $\left(\beta_{W_{i j}}^{\text {plants }} \times \beta_{W_{i j}}^{\text {pollinators }}=-7.92, p=0.009\right)$. These trends are very similar to those reported in the main text.

Considering only comparisons between webs in the same year, role dissimilarity for plants was not related to the amount of turnover in the plant or insect communities or the interaction between the two turnover terms $\left(\beta_{W_{i j}}^{\text {plants }}=-4.82, p=0.346 ; \beta_{W_{i j}}^{\text {pollinators }}=3.51, p=0.343\right.$; and $\beta_{W_{i j}}^{\text {plants }} \times \beta_{W_{i j}}^{\text {pollinators }}=-1.70, p=0.806$ for the regression including the interaction term and $\beta_{W_{i j}}^{\text {plants }}=-3.79, p=0.185 ; \beta_{W_{i j}}^{\text {pollinators }}=4.16, p=0.104$ when the interaction term was removed). For insects, too, role dissimilarity between webs in the same year was not related to turnover in the plant community, insect community, or the interaction between them $\left(\beta_{W_{i j}}^{\text {plants }}=-1.90\right.$, $p=0.626 ; \beta_{W_{i j}}^{\text {pollinators }}=3.96, p=0.193 ;$ and $\beta_{W_{i j}}^{\text {plants }} \times \beta_{W_{i j}}^{\text {pollinators }}=-0.996, p=0.860$ for the regression including the interaction term and $\beta_{W_{i j}}^{\text {plants }}=-2.47, p=0.262 ; \beta_{W_{i j}}^{\text {pollinators }}=3.55, p=0.070$ when the interaction term was removed). These relationships for insects are very similar to those presented in the main text while for plants the effect sizes are similar to those in the main text but the significance of the effect of insect turnover varied.

Considering only comparisons between webs describing the same month in different years, role dissimilarity for plants increased with increasing turnover in the insect community but was not related to turnover in the plan community or the interaction between the two 
turnover terms $\left(\beta_{W_{i j}}^{\text {plants }}=7.69, p=0.283 ; \beta_{W_{i j}}^{\text {pollinators }}=12.5, p=0.030 ;\right.$ and $\beta_{W_{i j}}^{\text {plants }} \times \beta_{W_{i j}}^{\text {pollinators }}=-$ $18.2, p=0.246$ for the regression including the interaction term and $\beta_{W_{i j}}^{\text {plants }}=-0.404, p=0.811$; $\beta_{W_{i j}}^{\text {pollinators }}=6.40, p<0.001$ when the interaction term was removed). Role dissimilarity for insects increased with increasing turnover in the insect community but was not related to turnover in the plant community or the interaction between the two turnover terms $\left(\beta_{W_{i j}}^{\text {plants }}=11.3, p=0.065 ; \beta_{W_{i j}}^{\text {pollinators }}=9.52, p=0.050 ;\right.$ and $\beta_{W_{i j}}^{\text {plants }} \times \beta_{W_{i j}}^{\text {pollinators }}=-20.8, p=0.131$ for the regression including the interaction term and $\beta_{W_{i j}}^{\text {plants }}=2.32, p=0.061 ; \beta_{W_{i j}}^{\text {pollinators }}=2.53$, $p=0.059$ when the interaction term was removed). Note that the relationship between dissimilarity in insects' roles was only significant when the interaction term was included in the regression. Both the effect sizes and significances in this case are different from those presented in the main text.

\section{Tentatively-dated observations in all webs in range}

When tentatively-dated observations were not included in the monthly webs, the amount of dissimilarity in plants' roles increased with increasing turnover in the insect community but was not affected by turnover in the plant community or the interaction between the two turnover terms $\left(\beta_{W_{i j}}^{\text {plants }}=0.648, p=0.776 ; \beta_{W_{i j}}^{\text {pollinators }}=4.41, p=0.012 ;\right.$ and $\beta_{W_{i j}}^{\text {plants }} \times$ $\beta_{W_{i j}}^{\text {pollinators }}=0.677, p=0.868$ for the regression including the interaction term and $\beta_{W_{i j}}^{\text {plants }}=1.01$, $p=0.178 ; \beta_{W_{i j}}^{\text {pollinators }}=4.65, p<0.001$ when the interaction term was removed). For insects, dissimilarity between roles in different monthly networks increased with increasing turnover in the insect community but was not related to turnover in the plant community or the interaction between the two turnover terms $\left(\beta_{W_{i j}}^{\text {plants }}=3.66, p=0.043 ; \beta_{W_{i j}}^{\text {pollinators }}=4.66, p=0.002\right.$; and $\beta_{W_{i j}}^{\text {plants }} \times \beta_{W_{i j}}^{\text {pollinators }}=-5.42, p=0.099$ for the regression including the interaction term and $\beta_{W_{i j}}^{\text {plants }}=0.894, p=0.157 ; \beta_{W_{i j}}^{\text {pollinators }}=2.60, p<0.001$ when the interaction term was removed). These trends for plants are very similar to those reported in the main text while the trends for insects differ.

Considering only comparisons between webs in the same year, role dissimilarity for plants' was not related to the amount of turnover in the plant or insect communities or the interaction between the two turnover terms $\left(\beta_{W_{i j}}^{\text {plants }}=0.338, p=0.937 ; \beta_{W_{i j}}^{\text {pollinators }}=0.965, p=0.692\right.$; and $\beta_{W_{i j}}^{\text {plants }} \times \beta_{W_{i j}}^{\text {pollinators }}=1.05, p=0.870$ for the regression including the interaction term and $\beta_{W_{i j}}^{\text {plants }}=0.990, p=0.530 ; \beta_{W_{i j}}^{\text {pollinators }}=1.29, p=0.376$ when the interaction term was removed). For insects, too, role dissimilarity between webs in the same year was not related to turnover in the plant community, insect community, or the interaction between them $\left(\beta_{W_{i j}}^{\text {plants }}=0.106\right.$, $p=0.974 ; \beta_{W_{i j}}^{\text {pollinators }}=0.721, p=0.743$; and $\beta_{W_{i j}}^{\text {plants }} \times \beta_{W_{i j}}^{\text {pollinators }}=1.23, p=0.812$ for the regression including the interaction term and $\beta_{W_{i j}}^{\text {plants }}=0.820, p=0.558 ; \beta_{W_{i j}}^{\text {pollinators }}=1.14, p=0.394$ when the interaction term was removed). These relationships for insects are very similar to those presented in the main text while for plants the effect sizes are similar to those in the main text but the significance of the effect of insect turnover varied.

Considering only comparisons between webs describing the same month in different years, role dissimilarity for plants increased with increasing turnover in the insect community but was not related to turnover in the plan community or the interaction between the two 
turnover terms $\left(\beta_{W_{i j}}^{\text {plants }}=4.36, p=0.537 ; \beta_{W_{i j}}^{\text {pollinators }}=14.6, p=0.006 ;\right.$ and $\beta_{W_{i j}}^{\text {plants }} \times \beta_{W_{i j}}^{\text {pollinators }}=-$ $12.4, p=0.419$ for the regression including the interaction term and $\beta_{W_{i j}}^{\text {plants }}=-1.19, p=0.487$; $\beta_{W_{i j}}^{\text {pollinators }}=11.0, p<0.001$ when the interaction term was removed). Role dissimilarity for insects increased with increasing turnover in the insect community but was not related to turnover in the plant community or the interaction between the two turnover terms $\left(\beta_{W_{i j}}^{\text {plants }}=9.40, p=0.090 ; \beta_{W_{i j}}^{\text {pollinators }}=10.3, p=0.016 ;\right.$ and $\beta_{W_{i j}}^{\text {plants }} \times \beta_{W_{i j}}^{\text {pollinators }}=-19.2, p=0.128$ for the regression including the interaction term and $\beta_{W_{i j}}^{\text {plants }}=1.22, p=0.282 ; \beta_{W_{i j}}^{\text {pollinators }}=4.25$, $p=0.003$ when the interaction term was removed). Note that the relationship between dissimilarity in insects' roles was only significant when the interaction term was included in the regression. Both the effect sizes and significances in this case are different from those presented in the main text. 


\section{Appendix A4 - Supplemental figures}

Figure A2: Unique positions in the two- to six-species motifs. Two- to four-species motifs are also shown in Fig. 1, main text. Positions with white fill can only be occupied by pollinators and positions with black fill can only be occupied by plants. Plants or pollinators indicated by the same number are interchangeable with regard to the motif under consideration.

2-species motif

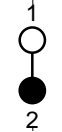

3-species motifs

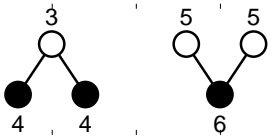

4-species motifs
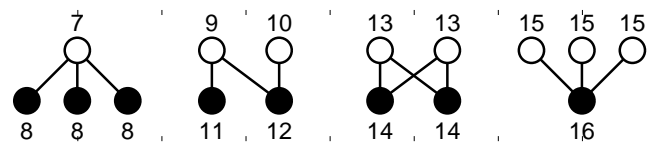

5-species motifs
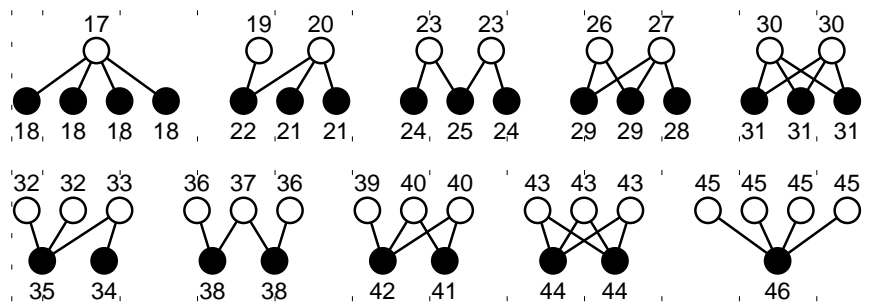

6-species motifs
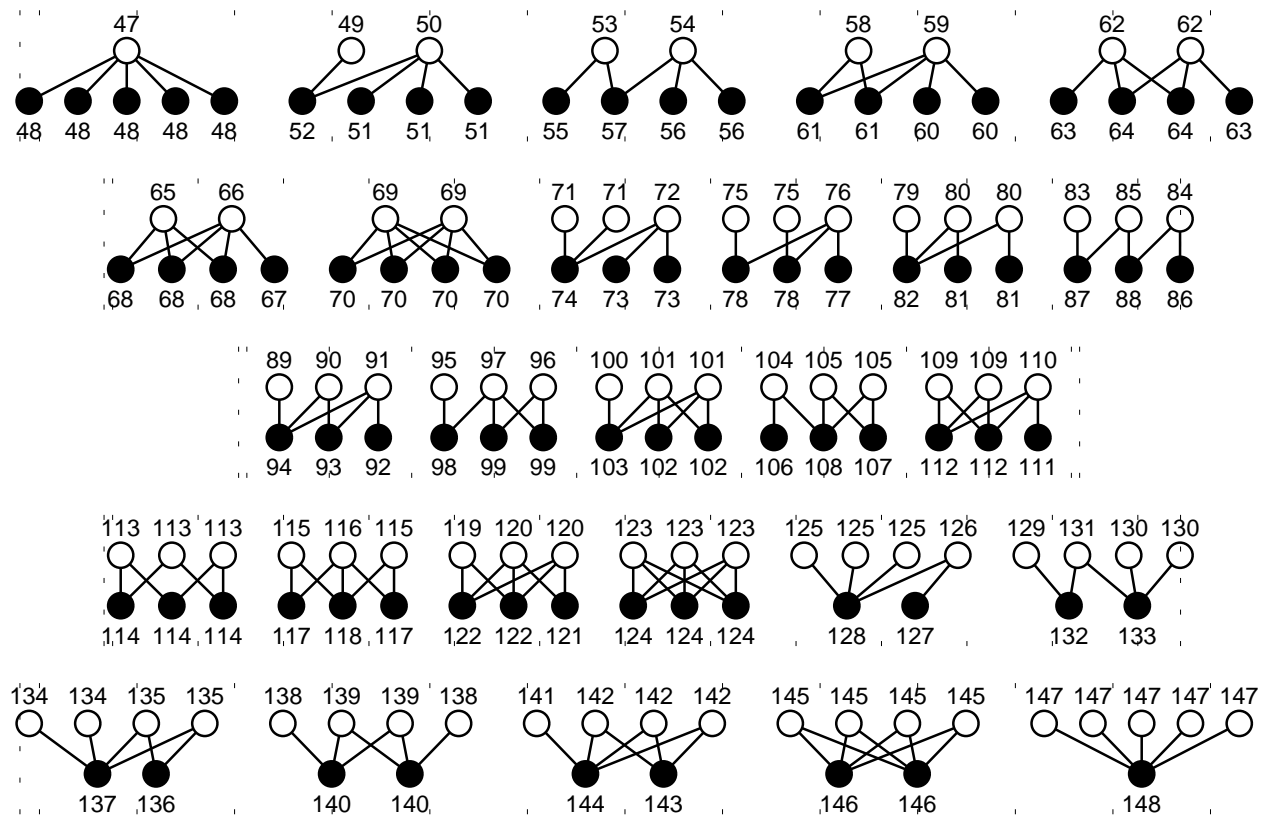
Figure A3: From 1996 to 2011, the composition of the Zackenberg plant-pollinator community changed between years. For each year, we show the number of plants (a) and pollinators (b) that were recorded in the previous year (solid), the number of species detected in the previous year that were not observed in the focal year (no fill), and the number of species that were detected in the focal year but not in the previous year (striped fill). The height of the bar indicates the total number of plants or pollinators observed each year. The majority of plant species were recorded in all four years. The pollinator assemblage, however, both increased in species richness and showed substantial turnover (Table S5, Appendix S4).
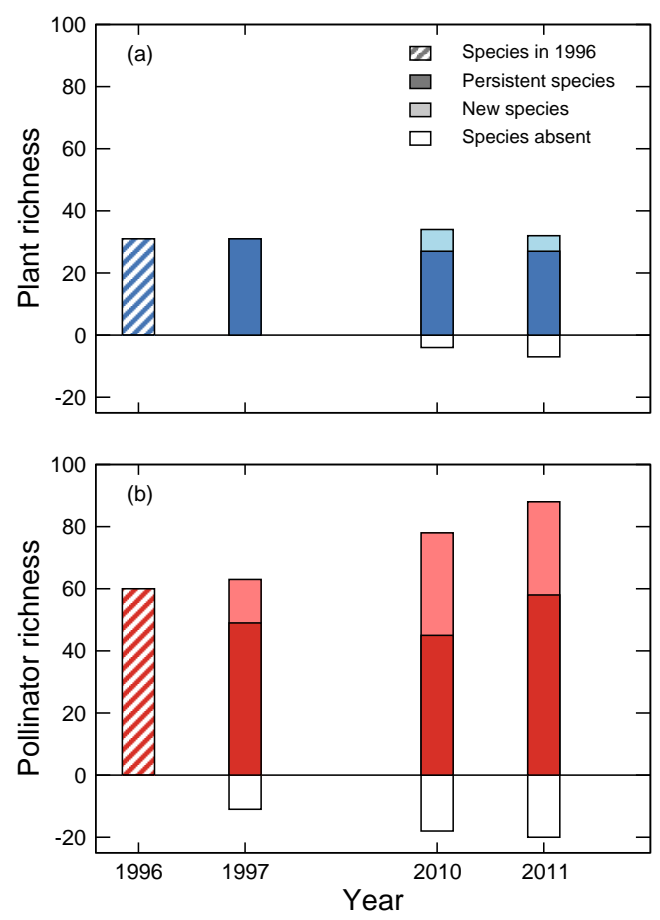
Figure A4: Here we show the loadings of each motif position on the two NMDS axes in Fig. S3. a-b) For both plants and insects, moving from negative to positive values of the second NMDS axis corresponded to decreasing frequencies of 2- and 3-species motifs and increasing frequencies of 6-species motifs. The first NMDS axis was not strongly related to motif size (indicated by shape). c-d) Positive values of the first NMDS corresponded to high frequencies of positions 30, 69, 123 (insects), 44, 124, and 146 (plants) while negative values of the first NMDS axis corresponded to high frequencies of positions 75, 125, 129, 130 (insects), 81, 73, and 127 (plants). Based on these positions, it appears that moving from negative to positive values of the first NMDS axis corresponds to a shift from high frequencies of positions describing specialists to high frequencies of positions describing generalists.

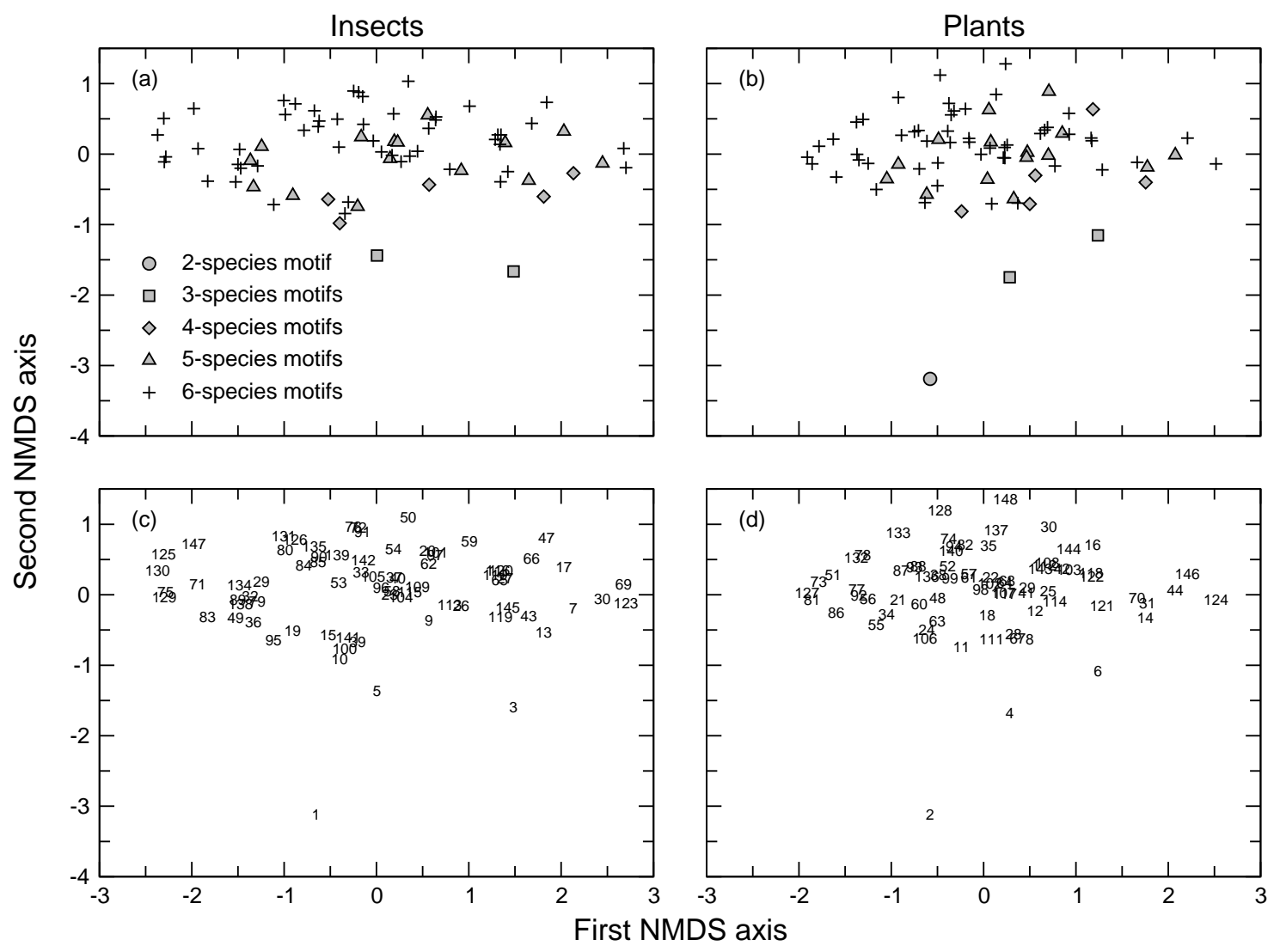


Figure A5: Considering only comparisons between monthly networks describing different months in the same year (i.e., within-year comparisons) dissimilarity in the roles of plants, but not insects, was related to the amount of community turnover. a-b) Dissimilarity in plants' roles increased with increasing turnover in the insect assemblage and was not significantly related to the amount of turnover in the plant assemblage. c-d) Dissimilarity in insects' roles was not significantly related to turnover in the plant or insect assemblages. For both plants and insects, a non-significant interaction term was removed from the model and the model re-fit. In panels (a) and (c) we show the observed relationship between role dissimilarity and insect turnover, while in panels (b) and (d) we show predictions based on the fixed effects of equation (1) (i.e., excluding random effects of species). We show predictions for the minimum and maximum observed plant turnover, as well as moderate values of turnover between the two extremes. Only predictions for combinations of plant and pollinator turnover observed in our data are depicted. Both observed data and prediction lines are coloured along the same scale, according to plant turnover.
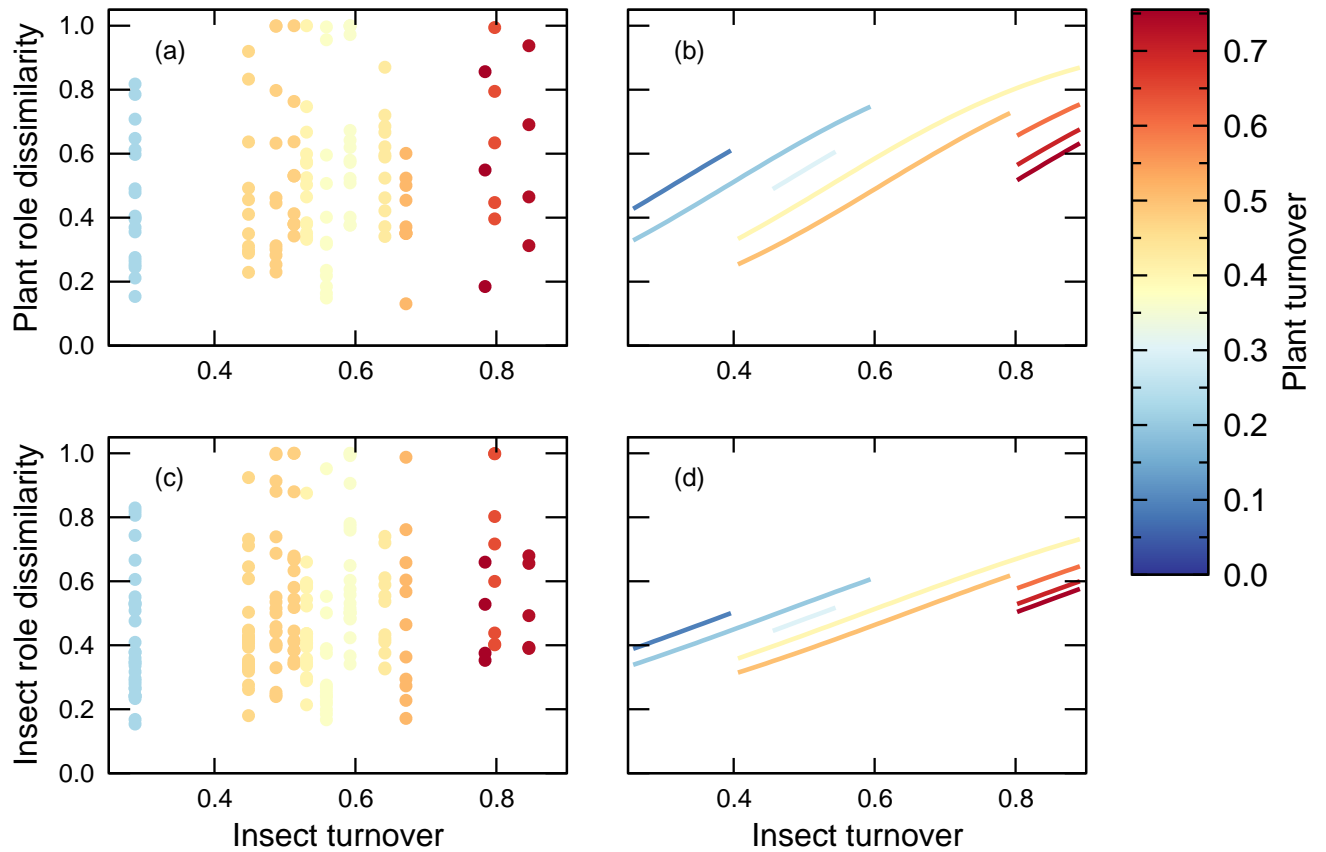
Figure A6: Considering only comparisons between monthly webs describing the same month in different years (i.e., between-year comparisons), dissimilarity in the roles of plants and insects was related to the amount of turnover in the insect assemblage. Only dissimilarity in plants' roles was related to the amount of turnover in the plant community and the interaction between the two turnover terms. a-b) Dissimilarity in plants' roles increased with increasing turnover in the plant and insect assemblages but decreased with the interaction between them. c-d) Dissimilarity in insects' roles increased with increasing turnover in the insect assemblage and was not significantly related to the amount of turnover in the plant assemblage. The interaction term between plant and insect turnover was not significant and was removed from the model. In panels (a) and (c) we show the observed relationship between role dissimilarity and insect turnover, while in panels (b) and (d) we show predictions based on the fixed effects of equation (1) (i.e., excluding random effects of species). We show predictions for the minimum and maximum observed plant turnover, as well as moderate values of turnover between the two extremes. Only predictions for combinations of plant and pollinator turnover observed in our data are depicted. Both observed data and prediction lines are coloured along the same scale, according to plant turnover.
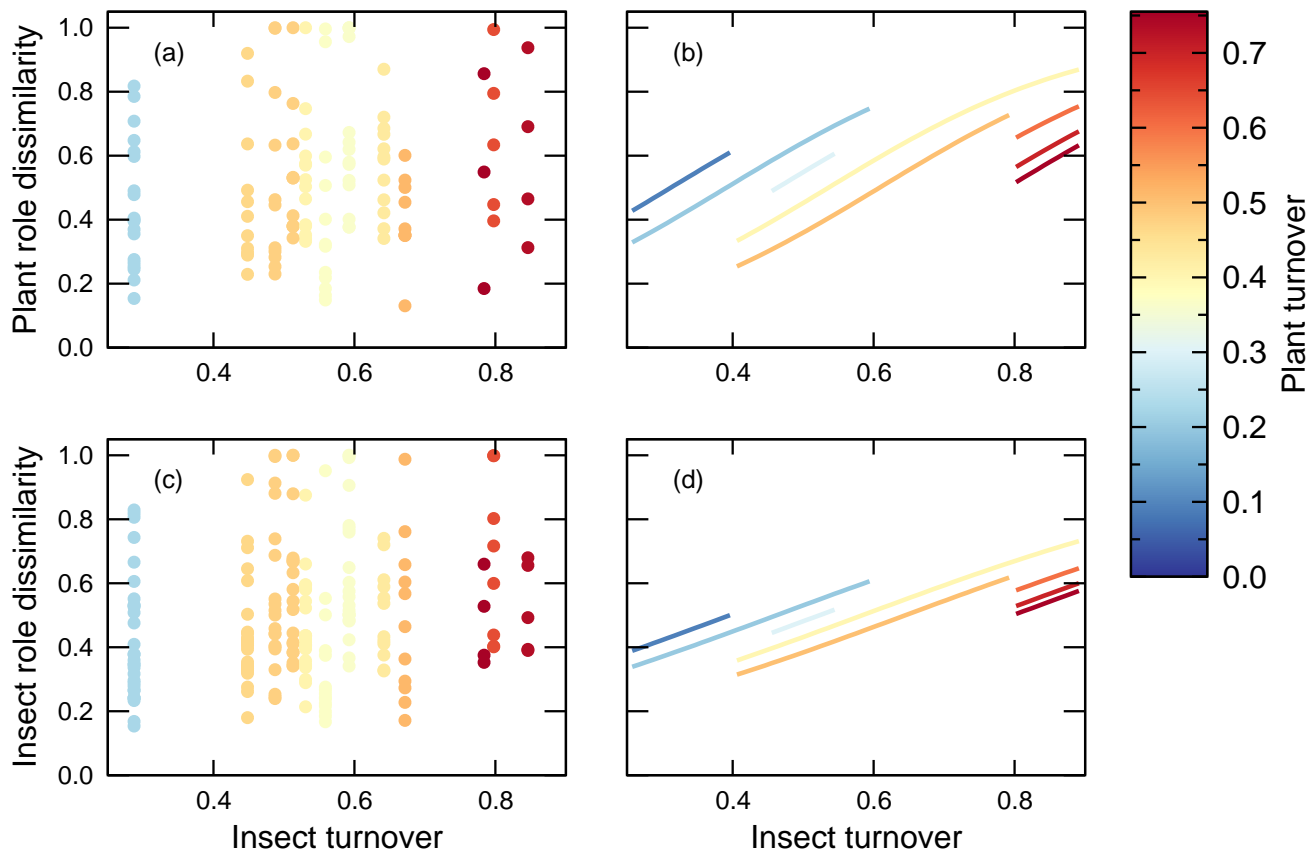

0.1

0.0 


\section{Appendix A5 - Supplemental tables}

Table A5: Turnover in the yearly networks at Zackenberg (measured using Whittaker's beta diversity index) was higher among insect pollinators than plants.

\begin{tabular}{llll}
\hline \multicolumn{2}{c}{ Years } & Plant turnover & Pollinator turnover \\
\hline 1996 & 1997 & 0.000 & 0.203 \\
1996 & 2010 & 0.169 & 0.391 \\
1996 & 2011 & 0.111 & 0.432 \\
1997 & 2010 & 0.169 & 0.362 \\
1997 & 2011 & 0.111 & 0.417 \\
2010 & 2011 & 0.182 & 0.301 \\
\hline
\end{tabular}

Table A6: Turnover within years in the monthly networks at Zackenberg (measured using Whittaker's beta diversity index) was higher among insect pollinators than plants. Turnover values shown below are for monthly networks including tentatively-dated observations only on networks including the best-guess date for each interaction.

\begin{tabular}{lllll}
\hline Year & \multicolumn{2}{c}{ Months } & Pollinator turnover & Plant turnover \\
\hline 1996 & June & July & 0.513 & 0.476 \\
1996 & June & August & 0.784 & 0.750 \\
1996 & July & August & 0.642 & 0.429 \\
1997 & June & July & 0.559 & 0.368 \\
1997 & June & August & 0.672 & 0.514 \\
1997 & July & August & 0.287 & 0.224 \\
2010 & June & July & 0.448 & 0.463 \\
2010 & June & August & 0.846 & 0.733 \\
2010 & July & August & 0.531 & 0.404 \\
2011 & June & July & 0.487 & 0.476 \\
2011 & June & August & 0.797 & 0.643 \\
2011 & July & August & 0.592 & 0.364 \\
\hline
\end{tabular}


Table A7: Turnover between years in the monthly networks at Zackenberg (measured using Whittaker's beta diversity index) was higher among insect pollinators than plants. Turnover values shown below are for monthly networks including tentatively-dated observations only on networks including the best-guess date for each interaction.

\begin{tabular}{lllll}
\hline Month & \multicolumn{2}{c}{ Years } & Pollinator turnover & Plant turnover \\
\hline June & 1996 & 1997 & 0.500 & 0.280 \\
June & 1996 & 2010 & 0.529 & 0.250 \\
June & 1996 & 2011 & 0.529 & 0.360 \\
June & 1997 & 2010 & 0.529 & 0.200 \\
June & 1997 & 2011 & 0.569 & 0.385 \\
June & 2010 & 2011 & 0.519 & 0.280 \\
July & 1996 & 1997 & 0.347 & 0.091 \\
July & 1996 & 2010 & 0.421 & 0.186 \\
July & 1996 & 2011 & 0.429 & 0.119 \\
July & 1997 & 2010 & 0.423 & 0.222 \\
July & 1997 & 2011 & 0.453 & 0.222 \\
July & 2010 & 2011 & 0.333 & 0.241 \\
August & 1996 & 1997 & 0.607 & 0.389 \\
August & 1996 & 2010 & 0.765 & 0.467 \\
August & 1996 & 2011 & 0.877 & 0.407 \\
August & 1997 & 2010 & 0.481 & 0.381 \\
August & 1997 & 2011 & 0.516 & 0.231 \\
August & 2010 & 2011 & 0.400 & 0.455 \\
\hline
\end{tabular}

